\title{
A Critical Review of the Physicochemical Properties of Lignosulfonates: Chemical Structure and Behavior in Aqueous Solution, at Surfaces and Interfaces
}

\author{
Jost Ruwoldt \\ RISE PFI AS, Høgskoleringen 6B, 7491 Trondheim, Norway; jostru.chemeng@gmail.com
}

Received: 30 October 2020; Accepted: 13 November 2020; Published: 16 November 2020

check for updates

\begin{abstract}
Lignosulfonates are bio-based surfactants and specialty chemicals, which are generated by breaking the near-infinite lignin network during sulfite pulping of wood. Due to their amphiphilic nature, lignosulfonates are used in manifold applications such as plasticizer, dispersant, and stabilizer formulations. Function and performance are determined by their behavior in aqueous solution and at surfaces and interfaces, which is in turn imposed by the chemical make-up. This review hence summarizes the efforts made into delineating the physicochemical properties of lignosulfonates, while also relating to their composition and structure. Lignosulfonates are randomly branched polyelectrolytes with abundant sulfonate and carboxylic acid groups to ensure water-solubility. In aqueous solution, their conformation, colloidal state, and adsorption at surfaces or interfaces can be affected by a range of parameters, such as $\mathrm{pH}$, concentration of other electrolytes, temperature, and the presence of organic solvents. These parameters may also affect the adsorption behavior, which reportedly follows Langmuir isotherm and pseudo second-order kinetics. The relative hydrophobicity, as determined by hydrophobic interaction chromatography, is an indicator that can help to relate composition and behavior of lignosulfonates. More hydrophobic materials have been found to exhibit a lower charge density. This may improve dispersion stabilization, but it can also be disadvantageous if an electrokinetic charge needs to be introduced at solid surfaces or if precipitation due to salting out is an issue. In addition, the monolignol composition, molecular weight distribution, and chemical modification may affect the physicochemical behavior of lignosulfonates. In conclusion, the properties of lignosulfonates can be tailored by controlling aspects such as the production parameters, fractionation, and by subsequent modification. Recent developments have spawned a magnitude of products and technologies, which is also reflected in the wide variety of possible application areas.
\end{abstract}

Keywords: lignosulfonate; lignin; surfactant; adsorption; dispersant

\section{Introduction}

Global warming and the depletion of resources make the shift to green technologies and a bioeconomy ever more important. Biobased platform and specialty chemicals are a crucial part of this shift. Lignin is the second most abundant biopolymer and use of lignin therefore bears immense potential. Only $1-2 \%$ of the $50-70$ million tons of technical lignin produced annually is used for value-added products [1], as most of it is burned in the process for heat and to recover chemicals [2]. Lignosulfonates are dominating the market of technical lignin with an estimated annual production of more than 1 million tons [3]. This highlights their importance to both established biorefinery industry and to the future of our bioeconomy.

Due to their versatile character, lignosulfonates are found in many different applications. The most common use is as a dispersant [4], which includes applications such as concrete 
plasticizers, drilling mud thinners, coal-slurry and dye dispersants [5]. In 1999, roughly 50\% of the annually produced lignosulfonates were used as admixtures in concrete [6]. Other application areas include chelating and complexation agents, soil conditioning agents, flotation agents, dust binders, and emulsion stabilizers $[4,5,7,8]$. Emulsion stabilization with lignosulfonates requires high shear during emulsification, as the effect on interfacial tension is less than that of commercial surfactants [9]. Still, lignosulfonates can produce highly stable emulsions, which has yielded applications for example in agrochemical formulation [4]. Experimentally explored but not fully commercialized are applications such as corrosion and scale inhibitors, $\mathrm{CO}_{2}$ flooding and enhanced oil recovery, as well as polymer precursors and additives [10-16].

Lignosulfonates are generated as a by-product during sulfite pulping of wood [17]. During this process, the "infinite" lignin network is broken down and sulfonate groups are introduced on the lignin. The degraded lignin is hence rendered water-soluble and can be separated from the cellulosic fibers and material. Lignin isolated by a different process may alternatively be sulfonated post-separation, e.g., as sulfonated or sulfomethylated Kraft, soda or hydrolysis lignin [18-20]. The original lignin structure is preserved to a certain degree, which endows lignosulfonates with its amphiphilic properties. In technical applications, lignosulfonates are usually found as the polyelectrolyte salt of the lignosulfonic acid. Anionic groups such as sulfonate and carboxylic groups ensure water solubility, while less polar groups, i.e., aromatic and aliphatic moieties, facilitate interactions with surfaces and interfaces. Due to their surface activity, lignosulfonates can be considered surfactants. However, their structure is lacking the one-dimensional hydrophilic-head hydrophobic-tails configuration as found in simpler surfactants. Given their poly-branched three-dimensional geometry [21], it comes to no surprise that the dispersant effect of lignosulfonates is frequently exploited.

Most applications for lignosulfonates are in aqueous phase, which makes hydrophilicity a necessary feature. Still, the hydrophobic property of lignosulfonates facilitates interactions with a second non-aqueous phase. The end-use therefore relies on the appropriate balance of the hydrophobic and hydrophilic property, which are in turn dictated by the chemical composition and structure. Tailoring platform and specialty chemicals from lignin by controlling the separation process and by post-separation chemical modification is a current subject of extreme interest [1,2,5,22-25]. Recent developments have hence yielded more specialized lignosulfonate products, which is, for example, reflected by a broader range of products on the hydrophobic scale [9]. Along with this, a better understanding of lignosulfonate behavior and characteristics is available. Aqueous-phase behavior, such as conformation, self-association, and adsorption, is strongly linked to the chemical composition and structure of the lignosulfonate surfactant. This review therefore summarizes the current understanding of the physicochemical properties of lignosulfonates, which may serve as a reference for fundamental research and application-oriented actors.

After introducing fundamental definitions and distinctions, the chemical composition and structure of lignosulfonates are addressed. Characterization techniques are furthermore covered to provide background information for later discussion. Fractionation procedures and techniques are discussed, as these are linked to characterizing lignosulfonates. The physicochemical characteristics of lignosulfonates are debated concerning the solubility in different solvents, aqueous phase behavior such as conformation, self-association, and precipitation, and adsorption at surfaces and interfaces. Lastly, the physicochemical properties are reviewed with respect to compositional differences, and chemical modification techniques are briefly introduced.

\section{Fundamentals}

\subsection{Definitions and Distinctions}

In this review, the term 'lignin' is used to refer to the pristine lignin found in untreated lignocellulose biomass, but also for addressing various modified and unmodified forms of technical lignin. The term 'technical lignin' describes the lignin-rich fraction as obtained after a biomass 
separation step. Such technical lignin may further be purified by removing other biomass constituents, such as residual sugars. Technical lignin may also be modified, for example by a depolymerization treatment or by chemically altering the type and abundance of functional groups.

The main lignin extraction processes are the sulfite, Kraft, soda, and solvent pulping [5,26], as illustrated in Figure 1 Each process produces a distinct lignin fraction, which may vary in overall composition, molecular weight, as well as type and abundance of different functional groups. Other processes exist for producing technical lignin, such as acid hydrolysis or steam-explosion treatment $[27,28]$. A distinct difference exists between the two latter and the separation processes listed in Figure 1. Pulping processes were developed for extracting the lignin to isolate a cellulose-rich solid mass, whereas biomass hydrolysis and steam-explosion treatment are often conducted to extract sugars for further processing, for example fermentation.

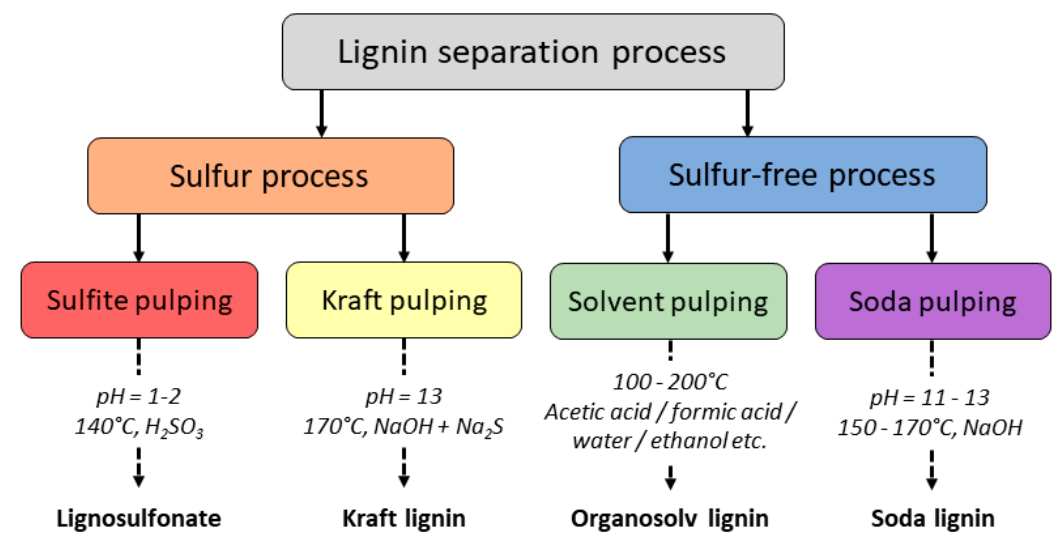

Figure 1. Lignin extraction processes and their dominant products according to Laurichesse and Avérous (modified) [26].

In accordance with the above definition, sulfonated lignin is produced by chemical modification of a lignin separated by a process other than sulfite pulping. A variety of modification processes exist for lignosulfonates [1], due to which the differences between lignosulfonate and sulfonated lignin can be marginal.

A surfactant (surface-active-agent) is a compound that lowers surface or interfacial tension between a liquid and another phase [29]. This effect is generally accompanied by surface or interfacial adsorption, i.e., an enrichment of the surfactant at the phase boundary [30]. As lignosulfonates are known to reduce surface and interfacial tension, they are surfactants by definition.

\subsection{Chemical Composition and Structure}

During the biosynthesis of lignin, three distinct monolignol units are interlinked by radical coupling reactions, i.e., $p$-coumaryl, coniferyl and sinapyl alcohol [31]. As shown in Figure 2, these monolignols correspond to the $p$-hydroxyphenyl $(\mathrm{H})$, guaiacyl $(\mathrm{G})$ and syringyl $(\mathrm{S})$ phenylpropanoid units and will further be addressed by their according letter. The macromolecular structure of lignin can hence be explained in terms of these monolignol units $[2,23,32,33]$, which are in a random poly-branched arrangement coupled by oxygen and carbon-carbon bonds. The most common linkage is the $\beta-\mathrm{O}-4$ ( $\beta$-aryl ether), while other linkages include $\beta-5, \beta-\beta, 5-5,5-\mathrm{O}-4$, and $\beta-1$ [31]. The $\beta-\mathrm{O}-4$ linkage is considered to be cleaved the easiest during pulping of lignocellulose biomass, which has implications for both the process and the resulting product. For example, lignin with predominantly $\mathrm{G}$ units is more resistant to chemical pulping than lignin that additionally contains $S$ units, since the latter is lacking one coupling site for the formation of carbon-carbon bonds [31]. The biomass separation process may also affect the type and abundance of inter-monolignol linkages, as prolonged pulping can induce repolymerization, so-called condensation reactions [17]. This may alter the availability of functional groups, as phenolic hydroxyl groups are depleted [34]. Lignosulfonates are in particular affected by 
condensation reactions, which is reflected by the broad molecular weight distribution that can be encountered for this type of lignin [35].

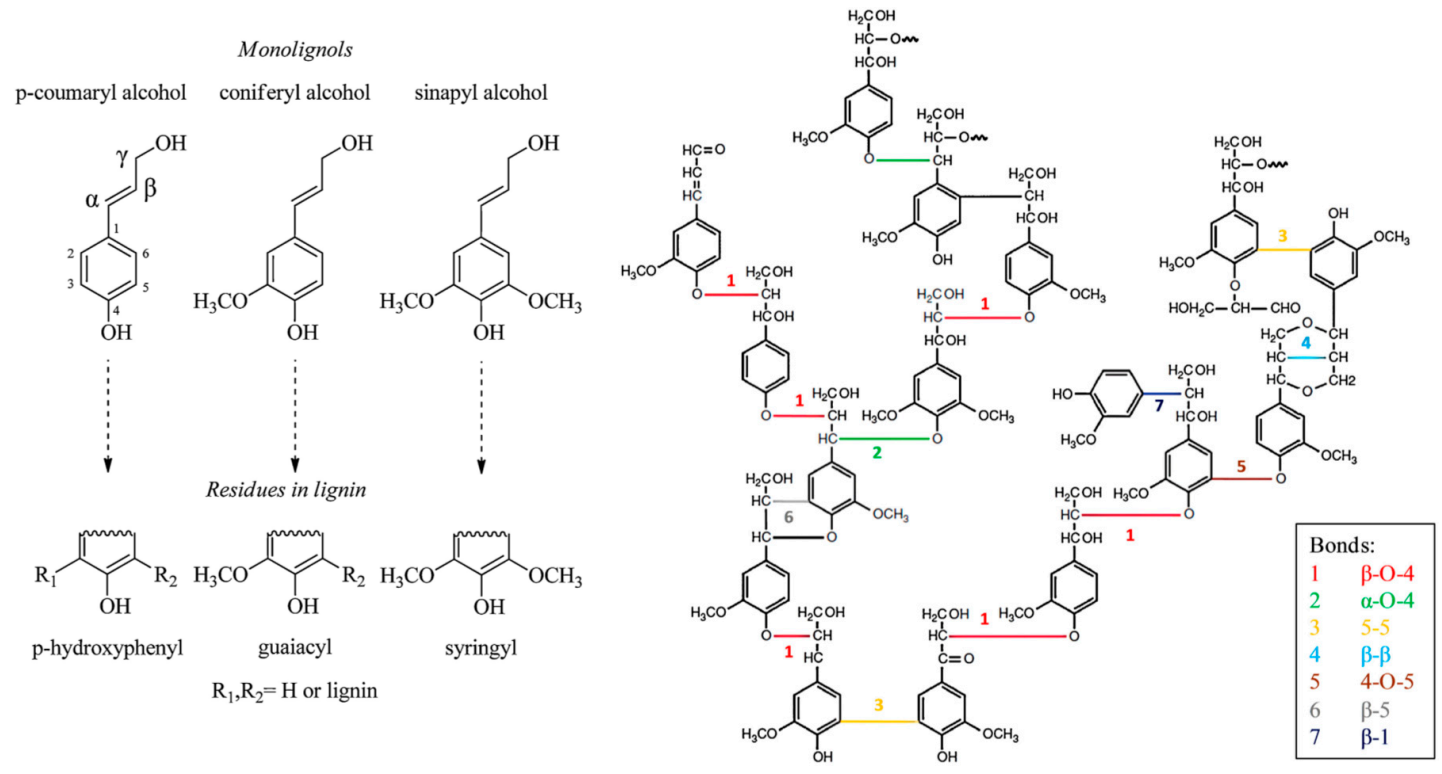

Figure 2. Primary lignin monomers and corresponding lignin units (left) [26]. Schematic structure of softwood lignin and bond types (right) [36].

Apart from their implications on the pulping process and product, the abundance of $\mathrm{H}, \mathrm{G}$ and $\mathrm{S}$ units is an important factor for the functional groups and hence the behavior and properties of technical lignin. Softwood lignin is predominantly composed of $\mathrm{G}$ units, while hardwood lignin contains both $\mathrm{G}$ and $\mathrm{S}$ units. Softwood lignosulfonate was consequently reported to react faster during free radical gelling reactions than hardwood lignosulfonate, which is due to the higher availability of free 5-positions in softwood lignin [37]. Softwood lignosulfonate was furthermore stated to be more salt-tolerant and to possess a solubility parameter closer to water than hardwood lignosulfonate [38].

Part of the original structure is preserved during lignin separation. Technical lignin may hence contain chemical bonds and functional groups such as ketones, ether bonds, hydroxy and methoxy groups [36,39]. Partial preservation of the monolignol structure yields abundant aromatic (phenolic) groups and residual aliphatic units that may resemble the original phenylpropene. The type of biomass separation or pulping process greatly affects the abundance of certain functional groups, and it may also introduce additional functionalities. For example, sulfite and Kraft pulping are known to introduce sulfonate groups [17]. Bleaching or oxidative processes may result in an increased number of carboxylic acid groups [40,41]. An overview of the most common chemical bounds and functional groups in technical lignin is given in Figure 3. This overview does not include groups that may additionally be grafted onto the lignin, for example by phosphorylation, alkylation, sulfobutylation or silylation [42].

Lignosulfonates are described as randomly branched polyaromatic polyelectrolytes [2,21], which exhibit water-solubility and surfactant-like behavior $[4,5,43]$. Hydrophilicity is imparted by the presence of anionic sulfonate groups, but also by anionic carboxylate groups and (at high $\mathrm{pH}$ ) phenolic hydroxyl groups [17]. The counterion is often a remnant from the pulping process, such as sodium, calcium, magnesium, or ammonia, which facilitates dissociation in aqueous solution. Apart from the dissociation equilibrium, the counterion may otherwise determine the physicochemical properties of lignosulfonates, for example by affecting the polymer conformation [44]. Some of the polar functional groups, i.e., ketones, aldehydes, and methoxy groups, are not operative hydrophilic groups [45]. Aliphatic hydroxyl and ether groups can be intrinsically hydrophilic; however, their functionality is determined by the surrounding molecular structure [45-47]. Two examples of generic lignosulfonate structures are shown in Figure 4. It should be noted that these are simplifications of a more complicated 
picture. Lignosulfonates should be considered to be statistical entities rather than classical chemical compounds, due to their polydisperse structure and molecular weight [48].

\begin{tabular}{lll}
\multicolumn{2}{c}{ Common functional groups found in technical lignin } \\
$\begin{array}{l}\text { Ionizable groups } \\
\text { Frequently found in their salt form }\end{array}$ & $\begin{array}{c}\text { Polar groups } \\
\text { Usually oxygen containing }\end{array}$ & $\begin{array}{c}\text { Nonpolar groups } \\
\text { Skeletal hydrocarbons }\end{array}$ \\
$\Rightarrow$ Sulfonate groups & $\Rightarrow$ Ether linkages & $\Rightarrow$ Aromatic moieties \\
$\Rightarrow$ Phenolic hydroxyl groups & $\Rightarrow$ Ketones & $\Rightarrow$ Residual aliphatic units \\
$\Rightarrow$ Carboxylic acid groups & $\Rightarrow$ Methoxy groups \\
& $\Rightarrow$ Aliphatic hydroxyl groups & \\
& $\Rightarrow$ Aldehydes
\end{tabular}

Figure 3. Commonly encountered chemical bounds and functional groups in technical lignin.
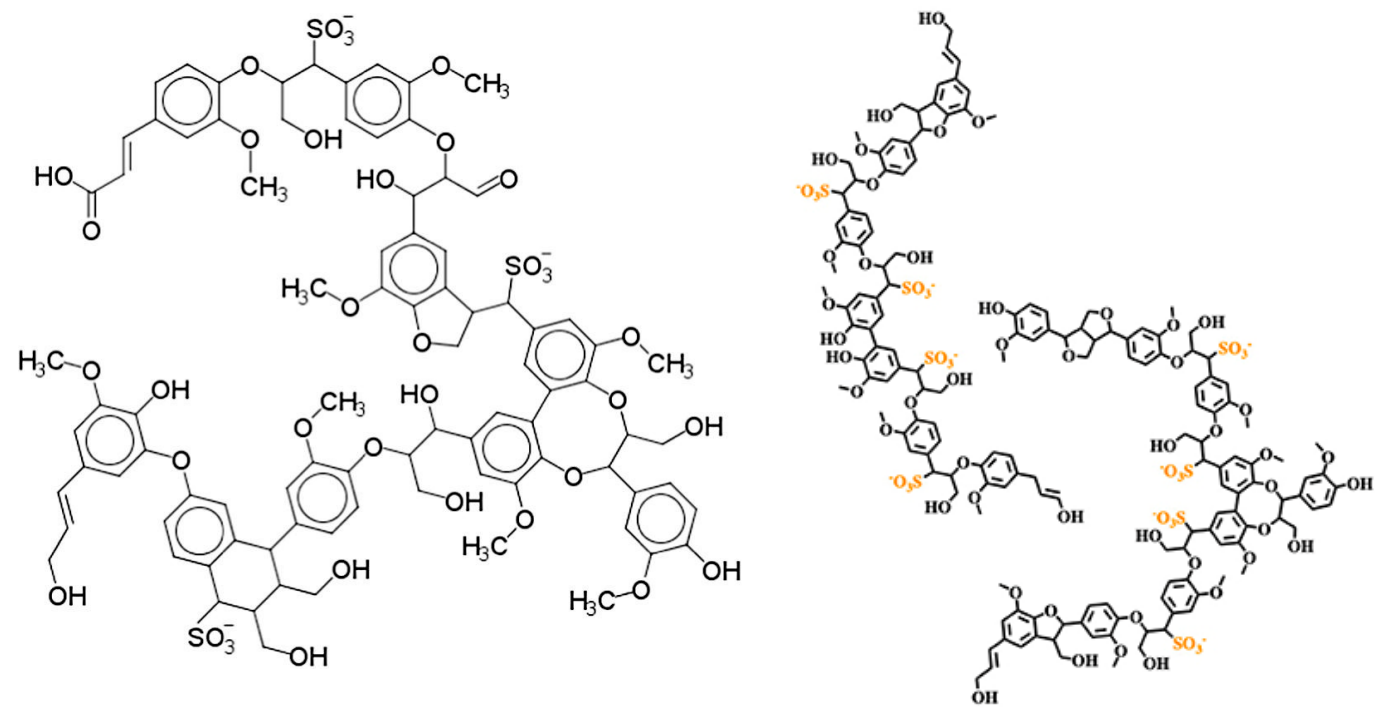

Figure 4. Generic (simplified) structure of lignosulfonates according to Kun and Pukánszky [49] (left), and Fiorani et al. [50] (right).

The molecular weight is furthermore an important factor determining the properties and behavior of lignosulfonates. For example, high molecular weight may cause stearic shielding of certain moieties [34]. It was shown that the degree of sulfonation decreased with increasing molecular weight [51]. The molecular weight is naturally linked to the molecular dimensions and the diffusion coefficient [52], which can further affect interfacial adsorption and related phenomena $[9,53]$. Overall, lignosulfonates may span from less than $1000 \mathrm{~g} / \mathrm{mol}$ to more than $400,000 \mathrm{~g} / \mathrm{mol}$ in molecular weight $[35,51]$. Acid hydrolysis lignin can possess mass average molecular weights $\left(\mathrm{M}_{\mathrm{W}}\right)$ on a similar scale, i.e., values of 1500-50,000 g/mol have been published [54]. However, technical lignin usually exhibits a lower $\mathrm{M}_{\mathrm{w}}$ and a less broad distribution, as for example in case of soda lignin (1000-15,000 g/mol), Kraft lignin (1500-25,000 g/mol) or organosolv lignin (500-5000 g/mol) [34]. An example for the molecular weight distribution of some lignosulfonates is plotted in Figure 5. As can be seen, the molecular weight distribution of the pure hardwood samples (LS6, LS7 and LS8) was consistently lower than that of lignosulfonates with softwood origin. This characteristic is likely resulting from the compositional differences of hardwood and softwood, which may furthermore determine the properties of the lignosulfonate product. 


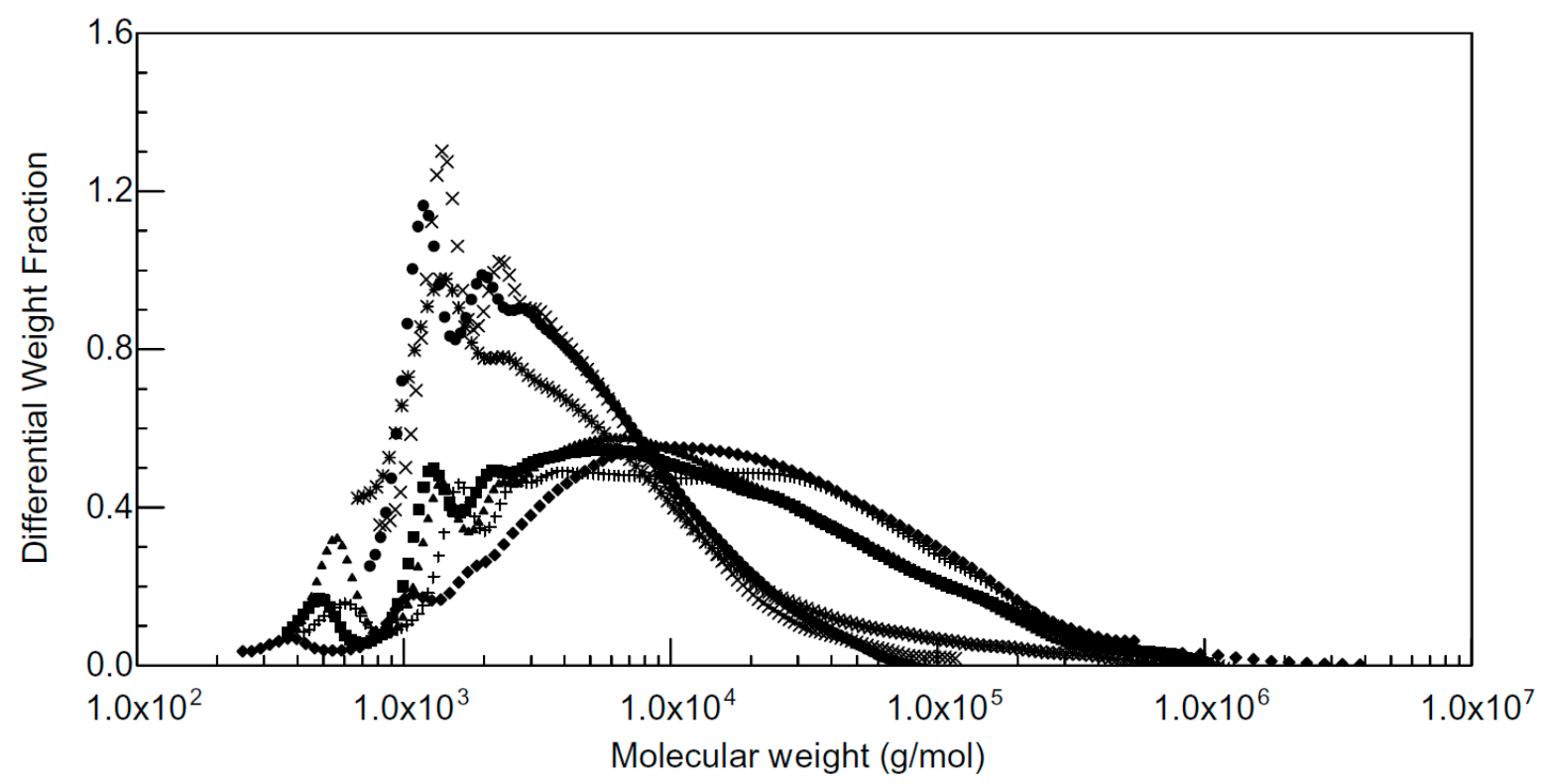

Figure 5. Molecular weight distribution of lignosulfonates originating from spruce [LS1 ( $\bullet)$, LS2 (๘)

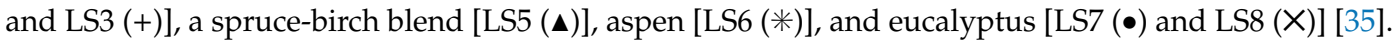

\subsection{Analytical Techniques for Lignosulfonate Characterization}

Characterization techniques for lignosulfonates may be grouped into three categories, which are (1) generic analytical techniques for lignin, (2) analytical techniques specifically developed for lignosulfonates, and (3) techniques for characterizing the solution, surface, or interphase behavior with application to lignosulfonates. Common examples for each category are provided; however, the goal of this section is to provide fundamentals and not to conduct a comprehensive review of analytical techniques.

A comparison of generic analytical techniques for lignin was done for example by Mansouri et al. [55,56]. Such characterization may encompass dry matter content, ash content, and elementary composition such as CHNS (carbon-hydrogen-nitrogen-sulfur) analysis. Inductively coupled plasma-optical emission spectrometry (ICP-OES) can be employed to determine the presence and abundance of metals and other elements, for example found as the cations of lignin-salts. For assessing the lignin purity, it can be helpful to measure the sugar content. The lignin purity may hence be assessed by determining the Klason lignin content [57], the acid-insoluble lignin [58], and the acid-soluble lignin [59]. Acid titration techniques can be used for structural investigations, for example by measuring the sulfonic and carboxylic acid content via the "acid number" or aqueous titration $[55,60]$. Fourier transform-infrared spectrometry (FT-IR) can detect certain chemical bounds and functional groups in lignin, such as hydroxyl, carbonyl, aldehyde, and sulfonic groups as well as C-C, C-O, and $\mathrm{C}=\mathrm{O}$ bonds $[55,61,62]$. Nuclear magnetic resonance (NMR) is also a powerful tool for determining various functional groups. Recent advances in 1H, 13C and 31P NMR have yielded more detailed characterization of the structure and chemical bonds found in lignin, including both biomass native and technical lignin $[63,64]$. Size-exclusion liquid chromatography (HPLC-SEC) is a long-established technique for studying the molecular weight distribution of lignin $[54,65,66]$. Other techniques to assess lignin molecular weight may include ultrafiltration [67], analytical centrifugation [65], mass spectrometry (MS) [68], and laser light scattering [69]. Pyrolysis gas chromatography (Py-GC-MS) is furthermore a technique that can provided detailed information about the chemical structure of lignin $[70,71]$.

An overview of important techniques for lignosulfonates has been given for example by Lebo et al. [72] or by Bruding and Schoenmakers [71]. Accurate determination of the molecular weight of lignosulfonates was enabled by advancing HPLC-SEC with in-line multi-angle laser 
light scattering (MALLS), which helped to overcome previous challenges, such as unrepresentative calibration standards, variations in refractive index, and fluorescence [35,51]. Asymmetric flow field-flow fractionation (AsFIFFF) coupled MALLS has recently been proposed as a new development for measuring lignosulfonate molecular weight [73]. Hydrophobic interaction chromatography (HIC) first adsorbs lignosulfonates on a stationary phase, which is subsequently desorbed by using increasing ethanol concentrations in the eluent $[33,74]$. It has recently been demonstrated that both the average molecular weight from SEC and the relative hydrophobicity from HIC can have implications for technical applications, such as emulsification and emulsion stabilization [9]. The recent coupling of HIC with other analytical techniques showed that 2D-LC (HIC coupled SEC) may provide a superior technique for analyzing the structure of lignosulfonates [75]. The sulfonic acid group can be determined by NMR, conductometric titration, elemental analysis, and headspace GC-MS [76]. In addition, X-ray fluorescence spectroscopy has been proposed for the elemental analysis of lignosulfonates, as this may be used to target specific elements such as sodium, calcium, and sulfur, which are of particular importance to the end-use applications [72].

Characterizing the solution behavior or surface-adsorption frequently involves post-experimental quantification of the remaining lignosulfonate. For example, several researchers determined adsorption isotherms by contacting a lignosulfonate solution with a solid phase, separating the phases, and using UV-spectrometry to quantify the lignosulfonate concentration in the effluent or supernatant [77-81]. A similar separation-based procedure was also applied to quantify the amount of precipitated lignosulfonate due to salting out [9]. Probing lignosulfonate conformation and self-association in aqueous solution can be done by techniques such as rotary shear rheology, (anomalous) small-angle X-ray scattering, (dynamic) light scattering spectrometry, and fluorescence spectrometry [82-86]. Quartz crystal microbalance (QCM), spectroscopic ellipsometry, atomic force microscopy (AFM), and X-ray photoelectron spectroscopy have been suggested as alternatives for investigating the adsorption of lignosulfonates on solids [87-89]. Contact angle measurements can provide information on the effect on lignosulfonates on wettability of a solid surface [90,91]. Moreover, the zeta potential of suspensions and emulsions provides information about the adsorption and stabilization mechanism of lignosulfonate dissolved in the continuous (aqueous) phase [32,92,93]. Surface adsorption at the water-air interphase can be studied based on surface tension measurements [94-96]. Analogously, the effect of lignosulfonates on interfacial tension, usually between a water and an oil phase, has been studied by spinning drop tensiometer, pendant drop tensiometer, and du Noüy ring method $[53,97,98]$. Langmuir-Blodgett experiments or interfacial shear rheometry are further going techniques for investigating the response of interfacial lignosulfonate layers to mechanical deformation or compression $[53,99]$.

\subsection{Fractionation}

Fractionation procedures will be discussed in this section, as they generally exploit differences in physicochemical properties within a given lignosulfonate sample. Such differences exist, for example, in the adsorption behavior, solubility in organic solvents, molecular size, and the association behavior with cationic species $[67,100,101]$. Fractionation of lignosulfonates is frequently conducted for purification, characterization, or to study the behavior of a more monodisperse fraction.

Chromatographic separation, in particular size-exclusion chromatography, is predominantly used for analyzing the molecular weight distribution of lignosulfonates [51,65,72,102]. However, when collecting the eluent over a short elution interval, this technique may also be used to obtain a lignosulfonate fraction with low polydispersity $[103,104]$. Ultrafiltration finds application in lignosulfonate purification, as this is a convenient way of removing biomass residue of low molecular weight, such as sugars and organic acids [105]. By cascaded ultrafiltration with increasing pore size, this technique can also be used to fractionate lignosulfonate by molecular weight $[67,95,100]$.

Solvent fractionation of lignosulfonates has been reported as early as 1956 [106]. The authors desorbed lignosulfonates from a stationary using aqueous solutions at decreasing ethanol concentration, 
which yielded a fractionation by molecular weight. A similar procedure was done by Fredheim et al., who analyzed the resulting fractions by SEC-MALLS [51]. Duval et al. also used decreasing volumes of ethanol, but the lignosulfonate was only dispersed in a liquid phase without prior adsorption to a stationary phase [67]. This procedure could isolate a low-molecular-weight fraction; however, the medium- and high-molecular-weight lignosulfonates were not fractionated. Leger et al. fractionated ammonium lignosulfonates via stepwise desorption from a cellulose column using isopropanol-water mixtures with decreasing amounts of isopropanol [107].

Kontturi and Sundholm suggested fractionation of sodium lignosulfonate with long-chain aliphatic amines [108]. The primary, secondary, and tertiary amines were dissolved in organic solvent and ionized with $\mathrm{HCl}$ to extract lignosulfonate from the aqueous phase via ion exchange. The extracted fraction was further retrieved by back-extraction using a sodium hydroxide solution. Depending on the organic solvent or aliphatic amine, the extraction could be selective towards high- or low-molecular-weight lignosulfonates. In two subsequent publications, Kontturi et al. developed this technology to perform lignosulfonate fractionation via liquid membranes $[109,110]$. Kienberger et al. used the same principle, i.e., lignosulfonate extraction and fractionation with alkyl-amines, while employing a cellulose membrane for phase separation [101].

\section{Physicochemical Properties of Lignosulfonates}

\subsection{Solubility in Different Solvents}

In contrast to other technical lignin, lignosulfonate possesses good water solubility due to an abundance of sulfonate groups [111]. Solutions of $53 \mathrm{wt} . \%$ in water have been reported [112], which would entail that the water-solubility of lignosulfonate is virtually unlimited. Myrvold further studied the solubility of different lignosulfonate samples in various solvents [38,43]. The author showed that apart from water, lignosulfonates also possess good solubility in ethylene glycol, propylene glycol, dimethyl sulfoxide (DMSO), as well as methanol-water and dioxane-water blends with more than $20 \%$ water. Limited solubility was reported for dimethyl formamide, methanol, cyclohexylamine, and acetic acid. It was concluded that hardwood lignosulfonates have Hansen solubility parameters further away from water than softwood lignosulfonates [38,43]. Solubility in ionic liquids at $90{ }^{\circ} \mathrm{C}$ has furthermore been demonstrated, such as choline acetate, tributylmethylphosphoniummethyl sulfate or $N$-butyl- $N$-methylpyrrolidinium dicyanamide [113].

\subsection{Conformation and Shape in Aqueous Solution}

An early model of the lignosulfonate conformation in aqueous solution was given by Rezanowich and Goring [114]. Based on light scattering and viscosity measurements, a microgel model was developed. The authors further proposed that the free charges were only located on the surface of the spherical molecule, as is illustrated in Figure 6. These assumptions were later refuted or refined. Following the polyelectrolyte expansion of lignosulfonates in dependence of molecular weight, Myrvold concluded that the randomly branched polyelectrolyte model provided the best description [21]. This suggested that the lignosulfonate is not a microgel structure. In addition, the spherical conformation only approximated the shape of low molecular lignosulfonate. At high molecular weight, the shape was better approximated by an "elongated or fully stretched shape" [21]. The conformation of lignosulfonates aqueous solution may indeed be better described as oblate spheroid shape $[83,115]$. 


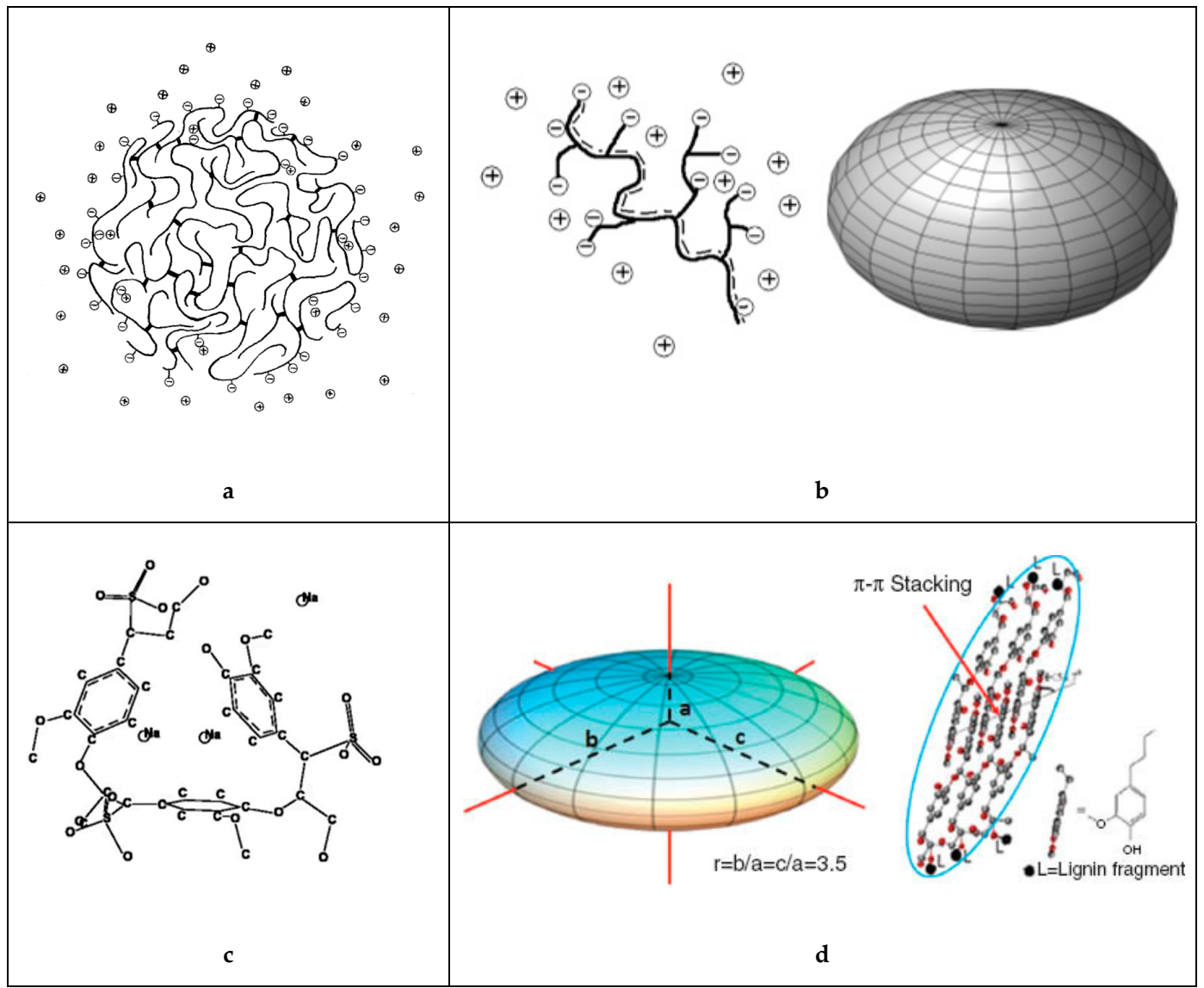

Figure 6. Idealized structure and shape of the sodium lignosulfonate macromolecule in solution according to (a) Rezanowich et al. [114] (top-left), (b) Myrvold [21] and Lauten et al. [4] (top-right), (c) Valencia et al. [44] (bottom-left) and (d) Qian et al. [115] (bottom-right).

At low salinity and low lignosulfonate concentration, the lignosulfonate molecule is expanded due to electrostatic repulsion between the anionic groups [116]. This expansion is dependent on ionic strength, as for example increasing counterion concentrations can reduce the dissociation-associated equilibrium. In addition, charge screening occurs at high salinity. Both effects reduce electrostatic repulsion and therefore lessen the degree of expansion. An additional effect governing polyelectrolyte expansion is the $\mathrm{pH}$ dependent dissociation. Lignosulfonate's sulfonate groups are mostly dissociated above $\mathrm{pH} 2$; however, the carboxylic groups ionize at about $\mathrm{pH} \mathrm{3-4}$ and the phenolic groups at around $\mathrm{pH} 9-10$ [86,117]. Increasing the $\mathrm{pH}$ from 2 to 10 was hence reported to increase the molecular dimensions [82]. Li et al. furthermore showed in dynamic light scattering experiments that the hydrodynamic radius of lignosulfonate molecules decreased at increasing temperature [118]. The entropy is higher at elevated temperature, which enables a larger number of possible conformations, thus also reducing the average molecular dimensions [116].

\subsection{Self-Association and Agglomeration in Aqueous Solution}

As any system that strives to minimize the total potential energy, lignosulfonates can aggregate in aqueous solution. It has long been suggested that this aggregation is the result of hydrophobic interactions [119], where the hydrophobic moieties are oriented towards the aggregate core and the hydrophilic moieties are concentrated on the aggregate surface. As a recent study on fluorescence excitation spectra showed, sodium lignosulfonate tends to form oriented $\pi$ - $\pi$-stacking with the spectroscopic characteristics of J-aggregates [120]. In addition, hydrogen bonding has been suggested as a mechanism for lignosulfonate-lignosulfonate attractive interactions $[83,118]$. Vainio et al. performed 
experiments on small-angle $\mathrm{X}$-ray scattering, which suggested that lignosulfonate molecules aggregate on the long edges into flat aggregates [85].

Reports are diverging on the geometry of the aggregates. One report stated that lignosulfonate aggregates are nearly spherical [119], whereas another report illustrated a hollow configuration [121]. As Myrvold demonstrated, aggregation and disaggregation of lignosulfonate is highly dependent on the preparation method and parameters, such as temperature, $\mathrm{pH}$, equilibration time, and concentration [122]. Both a condensed nearly spherical and an open-hollow configuration are therefore realistic.

Two schematics of the proposed mechanisms during lignosulfonate aggregation are shown in Figure 7. It should be noted that the geometrical representation for individual lignosulfonate molecules used by Vainio et al. [85], i.e., flat cuboid-like particles, is not consistent with the spheroidal conformation reported by other authors $[4,21,115]$.
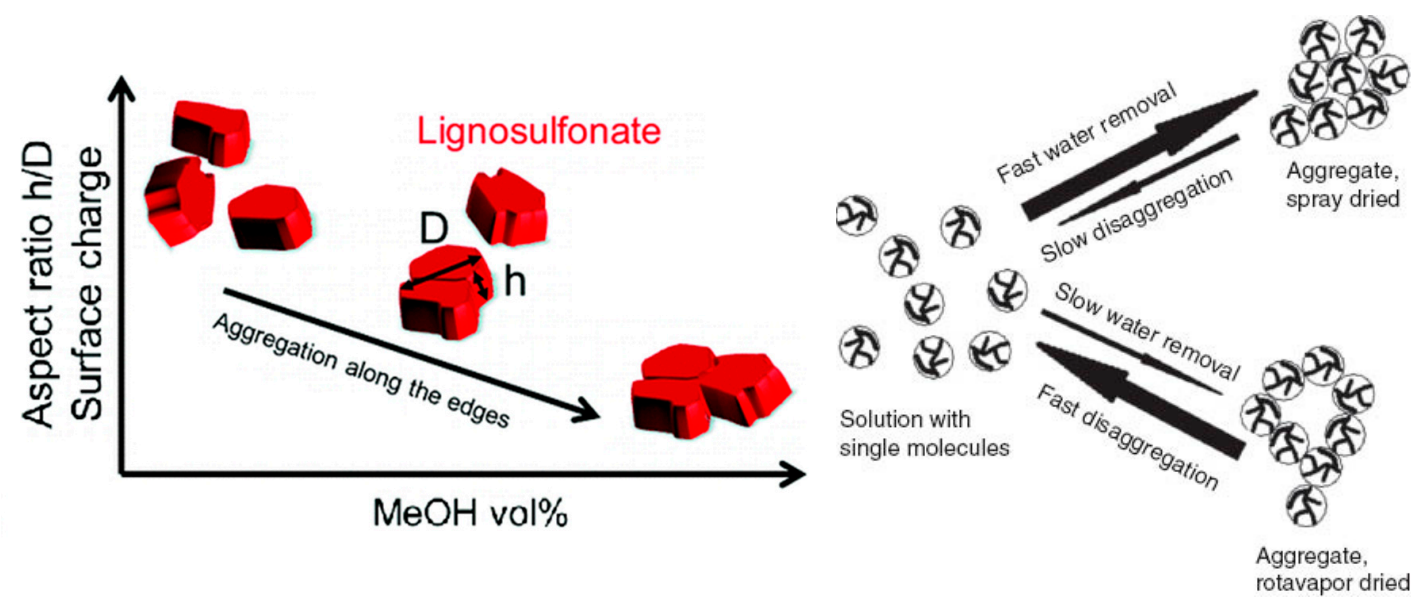

Figure 7. Lignosulfonate aggregation mechanism as proposed by Vaninio et al. [85] (left) or by Myrvold [122] (right).

Lignosulfonate aggregation can be induced by increasing lignosulfonate or salt concentration, by adding alcohol, by reducing $\mathrm{pH}$, and by increasing the temperature $[82,85,123]$. A common denominator among most of these actions is that electrostatic repulsion is reduced, which may further enhance hydrophobic interactions.

Increasing the concentration of lignosulfonate or of another added electrolyte will increase the ionic strength. This can induce Coulomb shielding of the anionic groups or yield a lower degree of dissociation. Electrostatic repulsion between individual lignosulfonate molecules is reduced and less hydrophilic moieties will be more exposed due to a larger number of possible conformations [116]. Both effects can facilitate hydrophobic interactions, which can lead to aggregation. Adding an alcohol solvent to the aqueous solution can have a similar effect, as the overall dielectric constant is reduced leading to a lower degree of dissociation of the anionic groups. This has been shown for example by addition of methanol, which yielded a reduction of the relative permittivity in proximity of lignosulfonate molecules [85].

Lignosulfonate aggregation was also reported to be caused by a temperature increase to $38^{\circ} \mathrm{C}$ and above [123]. This was accompanied by a reduction of the zeta potential [123], which would be coherent with a lower degree of dissociation [52]. As discussed previously, increasing the temperature will reduce the polyelectrolyte expansion of lignosulfonates, as a higher number of conformations become thermodynamically possible $[116,118]$. Such behavior would naturally facilitate aggregation, as the hydrophobic moieties become more exposed. It is interesting to note that the overall charge was affected, even though the differences in dielectric constant and dissociation constant are small [116].

The $\mathrm{pH}$ can especially affect the dissociation of anionic functional groups in lignosulfonates. Tang et al. reported that disaggregation of sodium lignosulfonate can occur above $\mathrm{pH} 10.34$ [82]. 
It was argued that ionization of the phenolic groups increased electrostatic repulsion between the lignosulfonate molecules, leading to breakup of the aggregates. These results are in contrast to Yan et al., who found that increasing the $\mathrm{pH}$ from 3 to 12 yielded a steady increase of reduced viscosity [86]. All in all, lowering the $\mathrm{pH}$ could in theory promote aggregation; however, precipitation is more commonly observed as the result of $\mathrm{pH}$ reduction.

Classical surfactants are composed of a hydrophilic head and a lipophilic tail. This orderly arrangement accounts for rather defined properties, such as the critical micelle concentration (CMC). The analogous counterpart of lignosulfonates would be the critical aggregation concentration (CAC). Overall, reports on the CAC value of lignosulfonates are not consistent. Fluorescence spectrometry detected values between $0.15-0.24 \mathrm{~g} / \mathrm{L}$ in one case [124] and $0.05 \mathrm{~g} / \mathrm{L}$ in another case [86]. Rana et al. reported CAC values of 10-19 wt.\% deduced from surface tension measurements [96]. Park et al. determined a CAC of $24.8 \mathrm{~g} / \mathrm{L}$ by using the same technique [97]. Qiu et al. determined a CAC of $0.38 \mathrm{~g} / \mathrm{L}$ via UV-spectrometry [121]; however, the validity of this measurement is questionable, since UV-spectrometry does not provide a linear response (absorbance increase per concentration increment) at high lignosulfonate concentrations. Overall, lignosulfonate aggregation and de-aggregation is a kinetic process that is especially affected by the origin and composition of the sample [122]. A certain difference in CAC is therefore to be expected between authors, who performed their measurements on dissimilar samples.

\subsection{Precipitation and Gelling in Aqueous Solution}

Lignosulfonate precipitation from solution can be caused by several changes that destabilize its solubility. The addition of another electrolyte can invoke precipitation by salting out [9]. As has been reported, the salting-out tendency for various ions is in line with both the Schulze-Hardy rule and the Hofmeister series $[9,112]$, with the exception of a few ions. It was further discussed that the observed effects could not be explained by the common ion effect or screening effects. Adding a solvent to an aqueous solution can cause precipitation of lignosulfonates as well [85,92], as there are many solvents that are miscible with water but pose as poor solvents for lignosulfonates [43]. Precipitation of technical lignin by $\mathrm{pH}$ reduction is a common method, for example to separate the lignin from alkali black liquor during wood pulping [17]. At $\mathrm{pH} 3$ or lower, both the phenolic and carboxylic acid groups are mostly undissociated [86,117], which can lead to lignosulfonate precipitation if the ratio of sulfonic to carboxylic acid groups is too low.

Gelling reactions and other chemical changes are an additional way of precipitating lignosulfonate from aqueous solution. This approach has been used by Myrvold to produce aqueous lignosulfonate gels, which could be soluble or insoluble in water [37]. The proposed reaction was a coupling of phenoxyl radicals, which was initiated by strong oxidizing agents. Compositional analysis in ${ }^{1} \mathrm{H}-\mathrm{NMR}$ showed a decrease in phenolic hydroxyl groups, which asserted the proposed formation of 4-O-5 crosslinks to form larger macromolecules. Gelation of aqueous lignosulfonate solutions in the presence of sodium dichromate or potassium dichromate has also been reported [125], which presumably follows a similar reaction mechanism due to the oxidative potential of the dichromate. A different technology is the gelling of ammonium lignosulfonates, which can be induced by subjecting a solution to elevated temperatures at a $\mathrm{pH}$ of 4 or lower [126]. It has been demonstrated that the rate of gelling and extent of crosslinking can be controlled by parameters such as the cooking temperature, $\mathrm{pH}$, lignosulfonate concentration, residual sugar content, and the addition of other crosslinking agents [127]. Interfacial gelling of lignosulfonates has been reported to occur in the presence of di- or trivalent cations [53]. This effect is likely the result of intermolecular bridging between anionic functional groups.

\subsection{Adsorption at Surfaces and Interfaces}

Adsorption and desorption of lignosulfonates follow a similar behavior as that of other surfactants. Langmuir isotherm has been reported by several authors to describe the equilibrium adsorption of lignosulfonates on solids [78,128-130]. At the water-air surface or 
water-oil interface, lignosulfonate adsorption is evident by a decrease in surface or interfacial tension $[9,94,131]$. This decrease follows a linear-logarithmic progression with increasing lignosulfonate concentration $[9,94]$, but above a certain concentration the effect can decrease in slope, which has been related to the aggregation onset by some authors $[96,97]$. Figure 8 exhibits two comparisons of surface tension plots for lignosulfonates with other surfactants and polymers.
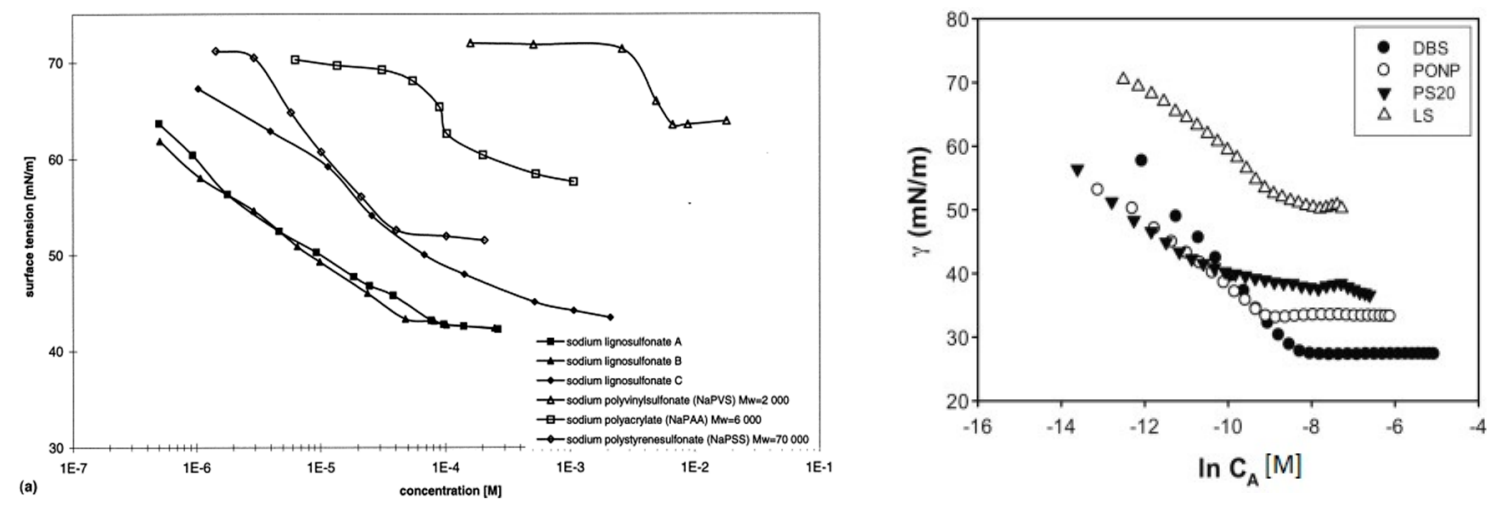

Figure 8. Equilibrium surface tension (water-air) in dependence of surfactant or polymer concentration. Comparison of lignosulfonates (LS) with polyelectrolyte polymers (left) [94] or with the surfactants dodecyl benzenesulfonate (DBS), nonylphenyl polyoxyethylene glycol (PONP, Ingepal CO-720) and polysorbate 20 (PS20, Tween 20) (right) [97].

Overall, lignosulfonate addition caused a larger reduction of surface tension than polyelectrolyte polymers, such as sodium polyacrylate or sodium polystyrenesulfonate [94]. On the other hand, less reduction of surface or interfacial tension than regular surfactants was reported [97,132,133], such as sodium dodecyl sulfate or nonylphenyl polyoxyethylene glycol. Reports are contradictory on the effect of molecular weight. One study stated that lignosulfonates with a lower average molecular weight displayed a tendency to induce larger changes of interfacial tension [9], whereas another reported that with increasing molecular weight the effect on surface tension became stronger [95]. The reduction of surface or interfacial tension can further be enhanced by increasing ionic strength or by reducing the $\mathrm{pH}[53,86,131]$.

Measurements of surface or interfacial tension are also instrumental for studying the kinetics of lignosulfonate adsorption. Several hours or more are usually needed to attain an equilibrium state $[53,98,132]$. To explain this comparably long equilibration time, it was proposed that lignosulfonate molecules undergo diffusion exchange at the interface, and that individual molecules are subject to rearrangement with respect to the interface and to each other [53]. Such conformational realignment has for example been described for petroleum asphaltenes at the water-oil interface [134,135]. Both lignosulfonates and asphaltenes are poly-branched and exhibiting a tendency for self-association. In addition, lignosulfonates and petroleum asphaltenes have in common that emulsions stabilized by these components require overnight storage before processing $[9,136]$, as the emulsions would otherwise be less stable. These two species have hence been compared in terms of interfacial phenomena [53].

The dynamics of lignosulfonate adsorption at the air-water interface was studied for example by Yan and Yang [131], who showed that the adsorption kinetics are faster at low $\mathrm{pH}$ or at high ionic strength. The authors furthermore measured Langmuir surface compression isotherms and proposed a generalized model, which is shown in Figure 9. This model suggested a closer packing density facilitated by increased lignosulfonate concentration or higher ionic strength. This is in agreement, for example, with findings that suggest a smaller area per molecule at the interface at high salinity as compared to the low salinity condition $[9,53]$. In addition, an alignment of charged moieties into the aqueous phase is suggested, while the hydrophobic moieties are partly extended into the non-aqueous phase [131]. 

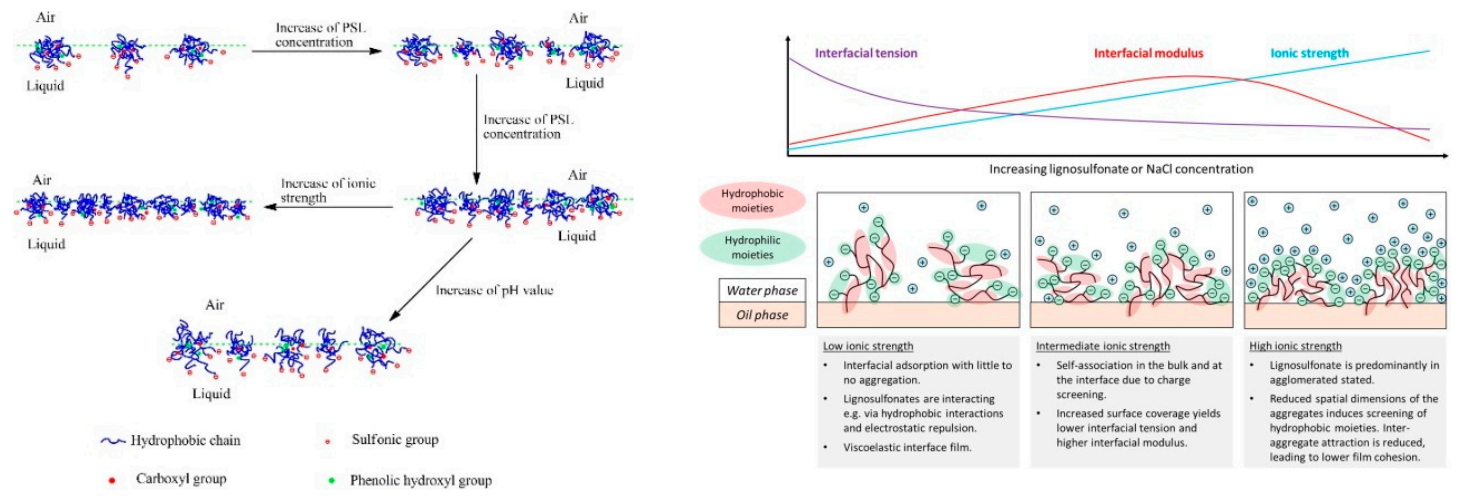

Figure 9. Model view of lignosulfonate adsorption according to Yan and Yang [131] (left) and Ruwoldt et al. [53] (right).

Fundamentally, the model view proposed by Yan and Yang is in line with the generally accepted theories; however, two statements were made that are in disagreement with other literature references, i.e., the formation of a monolayer film and the adsorption of (mono-) molecular lignosulfonate were proposed [131]. Gundersen et al. also studied lignosulfonate adsorption layers using the Langmuir technique [99], based on which the formation of multilayers was proposed. Lignosulfonate multilayers were also indicated in by deposition and self-association of lignosulfonate and cationic polymer on a solid substrate $[89,117,137]$. An alignment and thereby concentration of charged moieties in the aqueous phase would certainly make sense, as proposed by Yan and Yang [131], which could furthermore prevent a second or third layer from adsorbing due to electrostatic repulsion. However, lignosulfonate has proven an ability to form three-dimensional aggregates also, so it would be best to assume that both mono- and multilayer formation is possible. With regards to the adsorption of (mono-) molecular lignosulfonate, a recent study fitted the long-time approximation of Ward and Todai to dynamic interfacial tension data [53]. The diffusion coefficients were calculated in this manner, which were several magnitudes larger than that of non-aggregated lignosulfonate. In addition, the diffusion coefficients would decrease at increasing lignosulfonate concentration, which indicated that lignosulfonate underwent adsorption in the aggregated state. Regressions made with the Lucassen van den Tempel (LvdT) model furthermore showed a qualitatively poor fit. The shortcomings of both models suggested that some of the underlaying assumptions were insufficient, which led to the conclusion that lignosulfonate adsorption is not diffusion-limited [53].

The kinetics of lignosulfonate adsorption on solid surfaces have been investigated by several authors [128,129,138-141]. Bai et al. studied adsorption and desorption of calcium lignosulfonate on limestone or dolomite porous media, using core samples through which the surfactant solution was pumped [129,138]. A two-step pattern was identified, which consisted of initial fast adsorption or desorption, followed by a (second) slower step. A second-order kinetic model provided the best fit and it was concluded that desorption occurred slower than adsorption. Zulfikar et al. studied the adsorption of sodium lignosulfonate on eggshells or chitosan-silica beads $[128,139]$. Pseudo second-order kinetics fitted the data better than a first-order kinetic model as well, and intra-particle diffusion was reported as the rate determining step. Li et al. conducted adsorption experiments with sulfonated lignin acting as the solid (adsorbent) phase [142]. A hydrogel based on sulfomethylated Kraft lignin was synthesized, onto which cationic dye (methylene blue trihydrate) was adsorbed. Interestingly, the adsorption kinetics were also of pseudo second-order and exhibited Langmuir isotherm behavior at equilibration.

Dispersion stabilization is a frequent technical exploitation of lignosulfonate adsorption. This entails keeping a solid or liquid phase dispersed in another liquid phase, as for example in the case of concrete plasticizers (suspensions) or agrochemical formulations (emulsions) [4,143]. Several stabilization mechanisms have been proposed, which include electrostatic repulsion, stearic hindrance, particle stabilization (Pickering emulsion), and the formation of viscoelastic layers [53,92,144]. 
Electrostatic repulsion of droplets or particles is facilitated by the lignosulfonate adding negative charges at the surface or interface. This process can be monitored by measuring the electrophoretic mobility (zeta potential) of the dispersion, as has been done for suspensions of e.g., lead zirconate titanate [78], titanium oxide [32] or alumina [93]. Higher $\mathrm{pH}$ tends to induce larger changes of zeta potential, due to the higher degree of ionization of the functional groups of lignosulfonate $[78,93]$. It was suggested that a lower molecular mass can facilitate more efficient reduction of the zeta potential, due to screening effects of the sulfonate groups within larger lignosulfonate molecules [80]. Changes in molecular weight may, however, also be encompassed by differences in chemical make-up and functional groups [95], which can make it difficult to delineate the effect of lignosulfonate molecular weight on zeta potential.

Experimental evidence for the formation of a viscoelastic lignosulfonate film on solids has been reported by Qin et al. using QCM [87]. Dilatational interfacial rheology and interfacial shear rheology have been used to study the viscoelastic property of lignosulfonate films at the water-oil interface [53]. Factors such as lignosulfonate concentration, ionic strength, and type of added electrolyte were found to affect the properties of the surface or interfacial films. The film strength was studied in terms of the interfacial storage modulus and exhibited a maximum at intermediate salinity or intermediate lignosulfonate concentration. This reduction of the interfacial modulus at high salinity or high lignosulfonate concentration was attributed to either conformational changes and stearic shielding of non-ionic groups, or bulk precipitation as induced by the addition of di- or trivalent cations [53]. The presence of multivalent cations increased the film strength in particular, and interfacial gelling could be induced by these.

\subsection{Interactions with other Components}

The interactions with other surfactants and polymers are greatly determined by the presence of ionic functional groups, as electrostatic interactions are pronounced with the anionic groups of lignosulfonates. Studying inter-species interactions is by all means not trivial, as there are often counteracting effects. For example, association of lignosulfonates and cationic surfactants can yield cooperative adsorption [94]; however, such mixing may also cause precipitation, which would reduce the surfactant bulk concentration. At the interface, the adsorption of lignosulfonate and anionic surfactant would presumably be competitive due to electrostatic repulsion, but both species also increase ionic strength, which would drive the surfactants to the interface by salting out.

An early study by Ström and Stenius revealed that the interactions between lignosulfonate and cationic polyelectrolytes can lead to the formation of soluble complexes, colloids, and macroscopic precipitates [145]. The authors also included fractionated lignosulfonate in their study, which showed that lignosulfonate with a low molecular weight formed colloids only, whereas higher molecular weight yielded a flocculated precipitate. Fredheim et al. further studied the interactions between lignosulfonate and chitosan [146]. Association led to the formation of insoluble complexes with a sulfonate/amino ratio close to 1.0, from which it was deduced that all sulfonate groups were accessible for interactions with chitosan. No complex formation occurred at $\mathrm{pH} 8$, suggesting that it was indeed electrostatic interactions that govern the association of these two compounds.

Another approach for studying lignosulfonate interactions with cationic polymer is the build-up of multilayers by repeated immersion in a dipping solution. This self-assembly was reportedly driven by electrostatic interactions, hydrogen bonding, and cation- $\pi$ interactions $[137,147]$. Factor such as $\mathrm{pH}$, salinity, and lignosulfonate molecular weight had profound effect on the amount of adsorbed material $[89,117,137]$. In the study by Deng et al., a sharp rise in the adsorbed amount of lignosulfonate and increasing surface roughness was reported below $\mathrm{pH} 3.5$, which was attributed to the onset of ionization of carboxylic acid groups at and above this $\mathrm{pH}$ [117]. The lignosulfonate was present in a colloidal state at such low $\mathrm{pH}$. An investigation of the underlying kinetics furthermore showed faster adsorption at $\mathrm{pH} 3$, whereas $\mathrm{pH} 11$ yielded faster desorption. Ouyang furthermore reported that the addition of $\mathrm{NaCl}$ greatly increased the amount of adsorbed lignosulfonate, which was attributed 
to screening effects of the anionic groups [137]. Based on these results, the authors concluded that cation- $\pi$ interactions were the main driving force between self-association of lignosulfonate with the cationic polymer poly(diallyldimethylammonium chloride). Dynamic light scattering furthermore revealed smaller hydrodynamic radii at high salinity, which could contribute to a larger amount of adsorbed material as well. Using the same experimental setup, Deng et al. studied the effect of lignosulfonate molecular weight [89]. Five samples with low polydispersity index were obtained by gel column chromatography [103], which showed increasing portions of sulfonate groups with decreasing molecular weight [89]. Higher molecular weight of the lignosulfonate was found to lead to a slower adsorption rate, larger film thickness, and higher film roughness. These effects were associated with the differences in chemical structure of the lignosulfonate fractions, and by the increased hydrophobicity of the higher molecular weight samples. Layer-by-layer self-assembly was also demonstrated for chitosan and lignosulfonate, which showed increasing surface roughness and an exponential growth of adsorbed material with each coating [147].

As Askvik et al. showed by using surface tension measurements, interactions of lignosulfonate with cationic surfactant can indeed improve surface adsorption [94]. Precipitation was induced by increasing the concentration of the cationic species, but the solids were re-dispersed at even higher concentration due to charge reversal. This was shown by measurements of the electrophoretic mobilities of the complex phase. Askvik et al. furthermore used this cooperative association between lignosulfonates and water-soluble cationic surfactant to produce a complex phase with partial oil solubility [148].

Early studies on mixing of lignosulfonate with anionic surfactant have been conducted in the context of enhanced oil recovery (EOR) [149-151]. Hornof et al. blended lignosulfonates with different petroleum sulfonates, while also adding sodium chloride and 2-propanol [150]. The authors found that such four-component-mixtures could yield interfacial tension values as low as $1 \times 10^{-3} \mathrm{mN} / \mathrm{m}$. Adding 2-propanol to a high salinity solution showed no beneficial effect on interfacial tension, where it was argued that the system had surpassed the point of optimum salinity. Manasrah et al. documented that aqueous solutions of $4 \%$ petroleum sulfonates and $1.5 \% \mathrm{NaCl}$ blended with $1.4-1.5 \%$ lignosulfonates showed a pronounced increase in viscosity after aging [149]. The authors explained this phenomenon by the formation of liquid crystalline structures; however, in the presence of the right initiator, such behavior could also be explained by free radical gelling of lignosulfonates [37]. Application of lignosulfonates as sacrificial adsorbents for EOR has also been suggested [12,152], in which the beneficial effect is not attributed to lignosulfonate-surfactant interactions, but to adsorption and saturation of the empty sites on porous rock formations.

Rana et al. investigated the surface tension of lignosulfonate and sodium dodecyl sulfonate (SDS) surfactant [96]. Each of the tested lignosulfonate samples yielded a decrease of CMC of the SDS. The authors explained this behavior with the formation of mixed micelles; however, salting-out effects due to increased ionic strength after lignosulfonate addition would be a reasonable explanation as well.

An early study by Chiwetelu et al. investigated the surface and interfacial tension of lignosulfonate solutions, where specific attention was paid to the effect of adding $\mathrm{NaOH}$, butanol or acetone [13]. The addition of 1-butanol further reduced the interfacial tension of lignosulfonate solutions, which was also mirrored by improved oil recovery in displacement tests. The effect of straight chain alcohols on the adsorption behavior of calcium lignosulfonates was studied in detail by Qiu et al. [32]. The authors concluded that small amounts of straight-chain alcohols can improve lignosulfonate's surface activity and adsorption on $\mathrm{TiO}_{2}$ particles, where the largest effect was attributed to alcohols with a carbon chain-length of 10 or higher. Increasing adsorption and the effect on zeta potential could indeed be explained by cooperative adsorption. However, the ratio of alcohol to lignosulfonate was kept constant, which makes delineating the individual effect of the alcohol difficult in some instances. In contrast to this pronounced co-surfactant action long-chain primary alcohols [32], the presence of low-molecular-weight alcohols can also have profound effect on the performance of lignosulfonate as dispersion stabilizer [98]. Depending on concentration, the presence of methanol, ethanol or 2-propanol 
would either improve or reduced emulsion stability. The mechanism of action was not co-surfaction action, but a change in aqueous solvent properties. This was highlighted by the fact that high salinity diminished the beneficial effects of adding alcohol, which also suggested that affecting counterion condensation as reported by Vainio et al. is an important factor [85]. It was hence concluded that alcohol addition may effectively render the lignosulfonate more accessible for hydrophobic interactions, which can further improve the emulsion stabilization efficiency [98]. Although most reports suggested some degree of interaction between lignosulfonate and non-ionic surfactants, Askvik et al. concluded that lignosulfonate and non-ionic surfactants did not associate, due to the small contribution of hydrophobic interaction [94].

\subsection{Relationship between the Chemical Make-Up and the Physicochemical Behavior}

The physicochemical behavior of lignosulfonates, more specifically the behavior in aqueous solution and at surfaces or interfaces, is inherently linked to their chemical composition and structure.

The molecular weight has been discussed as one of the important parameters in the previous sections. Higher molecular weight naturally entails slower diffusion, which can further cause slower adsorption or desorption rates. In addition to that, a larger film thickness and higher film roughness were reported for higher molecular weight lignosulfonates [89]. Stearic screening of functional groups in high-molecular-weight lignosulfonates is an effect, which has been used to explain phenomena such as a lower effect on zeta potential by shielding of sulfonic acid groups [80] or a lower reactivity by screening phenolic hydroxyl groups [34]. Isolating lignosulfonate fractions with low polydispersity index has been done for more detailed and fundamental investigations [103]; however, the effect of high versus low polydispersity has been documented very little in contemporary literature.

There are also implications of the effect of molecular weight on the abundance of certain functional groups. Increasing molecular weight was reported by Fredheim et al. to entail a lower degree of sulfonation [51]. A publication by Yang et al. showed a first increasing and then decreasing amount of sulfonic acids groups [95], but the fractions differed slightly from Fredheim et al., while the overlapping molecular weight fractions showed the same trend [51,95]. The compositional differences are likely the reason that high-molecular-weight lignosulfonates have been described as more hydrophobic than low molecular samples [89]. Analyzing the composition of the different HIC elution peaks, it was demonstrated that the fractions eluted at the end (most hydrophobic) did indeed possess a higher average molecular weight than the earlier eluted fractions (less hydrophobic) [75].

It is widely established that the hydrophilicity of lignosulfonates is ensured by an abundance of sulfonate groups; by inversion of the argument, other technical lignin is usually not water-soluble, if there are insufficient ionizable groups. Less hydrophilic lignosulfonates are, for example, more prone to salting out [9]. Hydrophobicity on the other hand is an important parameter when considering the interactions with non-aqueous phases. HIC has been established as one of the techniques to quantify the hydrophobicity of lignosulfonates [33,72,74]. Better performance as stabilizer for suspensions [74] or oil-in-water emulsions [9] has been attributed to lignosulfonate samples with higher relative hydrophobicity. A recent publication by Musl et al. delineated the underlying implications of relative hydrophobicity [75], where it was reported that the charge to size ratio was governing HIC separation, i.e., the difference in sulfonation degree. It therefore appears that not necessarily an abundance of hydrophobic groups, but rather a lack of hydrophilic groups is promoting the dispersant capabilities of lignosulfonates.

Kraft lignin has been reported by some authors as more surface active than lignosulfonates [99]. Due to a different production (pulping) process, the sulfonation degree of Kraft lignin is on average lower than that of lignosulfonates [1]. It is, therefore, not surprising that a higher than average hydrophobicity has been reported for Kraft lignin [33]. The same study also indicated a higher hydrophobicity for a softwood lignosulfonate that had been oxidized; a process that can reduce the degree of sulfonation. It should be mentioned that sulfonic acid groups are not the only ones endowing 
the water-solubility, as studies have revealed a considerable amount of carboxylic acid groups in lignosulfonates as well $[95,153]$.

Due to a different plant species of origin, hardwood and softwood lignosulfonates differ in their monolignol composition. Hardwood consists of primarily $\mathrm{G}$ and $\mathrm{S}$ units, whereas softwood contains predominantly $\mathrm{G}$ units [26]. The $\mathrm{S}$ units contain two methoxy groups at the aromatic ring, which is one more than the $\mathrm{G}$ units. This may affect the pulping process, and hardwood lignosulfonates were for example reported to exhibit lower molecular weight ranges [35]. In general, the reactivity of softwood lignin is greater due to an additional free site at the aromatic rings of the $G$ units [37]. In theory, a greater abundance of methoxy groups could also affect the physiochemical behavior of hardwood lignosulfonates. Despite the lower average molecular weight, hardwood lignosulfonates have been reported to exhibit lower salt tolerance [38], which would entail that these are more hydrophobic than softwood lignosulfonates. However, it has not entirely been resolved if the difference between hardwood and softwood lignosulfonates are due to a different monolignol composition, or from the different manner in which these feedstocks are broken down during the sulfite pulping.

The effect of chemical make-up on the physicochemical behavior of lignosulfonates was explicitly studied on lignosulfonates that had been fractionated [95] or chemically modified [130]. Yang et al. fractionated softwood calcium lignosulfonate into five different size ranges by ultrafiltration [95]. The third fraction exhibited the largest sulfonic acid content, whereas the carboxylic acid content decreased with increasing molecular weight. As a total sum, the number of ionizable groups decreased progressively with increasing molecular weight, which would entail an according increase in hydrophobicity. The effect on surface tension, the amount adsorbed on titanium oxide particles, and the dispersion performance at high lignosulfonate concentration $(\geq 5 \mathrm{~g} / \mathrm{L})$ all increased progressively with increasing molecular weight, which would corroborate this trend in hydrophobicity. The effect on zeta potential did not follow the same trend, as fraction 3 showed the largest effect [95]. Such behavior was explained by a different author, who argued that screening of some charged moieties within higher molecular weight lignosulfonates occurred [80]. Pang et al. modified a softwood calcium lignosulfonate by oxidation, hydroxymethylation, and sulfomethylation [130]. The hydroxymethylated sample showed the strongest effect on surface tension, which could be explained by a higher hydrophobicity due to a higher ratio of hydrophobic methyl groups. The adsorption on solid surfaces was also improved; however, the dispersing performance of cement particles was reduced. Sulfomethylation is intended to add sulfonate groups, whereas oxidation can degrade the phenolic moieties and lead to the formation of carboxylic acid groups. Both actions can hence affect the anionic functional groups. A lower effect on surface tension at concentrations of $2 \mathrm{~g} / \mathrm{L}$ and below agree with a reduced hydrophobicity. Also, the adsorption to and stabilization of cement particles was improved, which were stated to carry a positive surface charge [130].

Not only the presence, but also the positioning and accessibility of certain functional groups may play a role in the characteristics of lignin. Especially lignin with high molecular weight may lead to stearic shielding of reactive functional groups, which are needed for example for subsequent polymerization reactions [34]. An example would be the oxypropylation of sodium lignosulfonate, as it has been conducted to increase reactivity with methane diisocyanate for lignin-polyurethane synthesis [154]. When considering the dispersant application of lignosulfonates, sulfobutylation (alkyl sulfonic acid grafting) has been conducted [155]. The lignosulfonates accordingly showed a high degree of sulfonation with $3.86 \mathrm{mmol} / \mathrm{g}$ and improved viscosity reduction of low-rank coal-water slurries. The underlying implication is that by placing the sulfonate groups on alkyl chains, these would not only be more accessible, but also possessed a higher degree of freedom, which could play out as a more effective anchoring effect and hence improve dispersion ability [155]. 


\subsection{Chemical Modification}

The chemical make-up of lignosulfonates can be influenced by controlling the production parameters during sulfite pulping, but also by post-separation modification [1]. Chemical modification of lignosulfonates is often done to serve one of two purposes, which are:

1. Modulation of the physicochemical properties, for example for improving the dispersant performance and compatibility. This can be done by addition or substitution of functional groups, but polymerization and depolymerization may be effective measures as well.

2. Improving the use in and compatibility with polymer formulations, for example by altering the abundance and accessibility of certain functional groups. Lignosulfonate may be incorporated as a quasi-monomer it into a larger polymer matrix. Use as filler material by blending the modified lignin with thermoplastic materials has also been demonstrated.

Chemical modification of lignin for use in polymeric materials has been reviewed extensively by other authors, for example by Matsushita [156], by Upton and Kasko [23], and by Wang et al. [157]. Aro and Fatehi reviewed the effect of production and modification method on the chemical makeup of lignosulfonates [1]. Grafting strategies for the hydroxyl groups of lignin has been reviewed by Eraghi et al. [42]. To avoid redundancy and as the focus of this review is on the physicochemical properties of lignosulfonate, there will only be a brief discussion on chemical modification strategies to provide a few examples within the context of this review.

As discussed in the previous sections, hydrophilicity and hydrophobicity are key factors that govern the efficiency of lignosulfonates as dispersants $[9,74]$. The hydrophobicity, as determined by HIC, was furthermore dependent on the composition, i.e., a higher abundance of ionizable groups indicated lower hydrophobicity and vice versa [75]. Lipophilicity can be introduced by grafting with non-polar alkyl chains, as was demonstrated by Thielmans and Wool [158]. The authors esterified Kraft lignin with different functional groups, where the butyrated sample exhibited solubility in styrene solvent. In more general terms, the properties of a surfactant depend on its hydrophilic-lipophilic balance [45]. It is trivial that this balance can be shifted, for example by adding ionizable moieties the surfactant can be rendered more hydrophilic; however, it is rarely pointed out that lignosulfonates are subject to such a balance. Chemical modification can hence be used to tailor lignosulfonates towards specific environments or applications by changing the hydrophilic-lipophilic balance. Commercial lignosulfonates are available on a broad range of relative hydrophobicity presently [9], which corroborates the necessity for such product tailoring.

It is general consensus that the dominant hydrophilic moieties of lignosulfonates are anionic functional groups, which most importantly comprises sulfonate groups, but also carboxyl groups and phenolic groups at high $\mathrm{pH}$ as well $[1,38,117]$. As discussed previously, the degree of sulfonation may be regulated by controlling the conditions during sulfite pulping of wood. In addition, post-pulping treatments that increase the amount of sulfonate groups have been proposed, such as additional sulfonation with sodium sulfite [159], sulfomethylation [130], and sulfobutylation [155]. Carboxylation can be the result of lignosulfonate oxidation [160], but grafting strategies have also been proposed such as esterification with maleic anhydride [161]. An increase in phenolic hydroxyl groups may be achieved by depolymerizing lignin, for example by hydrothermal or solvent treatments with homogeneous or heterogeneous catalysts, which cleave oxygen linkages between the monolignol units [162]. However, such treatment has less importance for dispersant applications of lignosulfonates, as the phenolic hydroxyl groups are usually not ionized at neutral $\mathrm{pH}$. Sulfonation and carboxylation can both increase the charge density of the lignosulfonate in aqueous solution, which may further affect its ability to stabilize dispersions.

Elevated relative hydrophobicity may result from a lack of ionizable functional groups [75], as discussed in the previous section. It would therefore be simple to increase the affinity of lignosulfonates to hydrophobic surfaces and interfaces by removing hydrophilic groups, as for example done by desulfonation during lignosulfonate oxidation [1]. A different strategy would be to 
add additional hydrophobic moieties. Reactions such as phenolation, esterification, and alkylation can introduce lipophilic moieties onto the lignin, such as aromatic and alkyl groups [42]. However, the practical use of such modification for lignosulfonates in dispersant applications has yet to be demonstrated.

The synthesis of a modified lignosulfonate was proposed by sulfomethylation, acylation, and the Mannich reaction with aliphatic polyamine [163]. Such modification was unique, as it would increase the abundance of both hydrophilic and hydrophobic moieties. The authors claim ultra-low interfacial tension as the result of the modification, i.e., values between $0.001-0.1 \mathrm{mN} / \mathrm{m}$, which would enable EOR application without added co-surfactant. However, no purification step was presented and the only measure for the reaction yield is the nitrogen content of the product [163]. The claimed effect of the modified lignosulfonate could therefore also be due to beneficial interactions with unreacted reagents.

Changing the molecular weight is also a type of chemical modification. A variety of processes have been suggested to further depolymerize technical lignin, which use acid, base, or metal catalysts and hydrothermal, solvent, or ionic liquid treatment at elevated temperature and pressure [162]. Molecular weight increase can be the result of condensation reactions [17], but also cross-linking reactions in the presence of bleaching chemicals were reported [37]. Enzymatic modification of lignosulfonates has recently been suggested, where modified laccase or horseradish peroxidase were used to increase the molecular weight $[164,165]$. The number of sulfonate groups remained unchanged, whereas a decrease in phenolic and aliphatic hydroxyl content was reported [165]. These changes could to some extend improve the adsorption on solids and the dispersant efficiency [165], but the effect on surface tension decreased after the treatment [164].

Oxidation is a treatment that can desulfonate lignosulfonates, effectively enhancing the hydrophobic character of the material [33]. In a more general context, oxidation of lignin can reduce the amount of phenolic groups while increasing the abundance of carboxylic groups [40]. The underlying reaction mechanism has been proposed to either a degrade of phenolic rings or to induce condensation reactions, depending on the reaction conditions [166]. This process can hence also be used to decrease or increase the molecular weight of lignin. Examples have been given, where oxidation of lignosulfonate has improved the efficiency as dispersion stabilizer [130].

\section{Summary and Conclusions}

Lignosulfonates are biobased surfactants and specialty chemicals, which are usually produced as a byproduct during sulfite pulping of wood. They are the technical lignin that is, by far, the most commercially traded and are hence vital for replacing non-renewable and fossil-based chemicals. Due to their prominent use as plasticizers, dispersants, and stabilizers, the physicochemical properties of lignosulfonates play a key role in determining their end-use and performance. This review is hence a critical and concise summary of the efforts, which were made to understand and delineate the behavior and properties of lignosulfonates in aqueous solutions, at surfaces and interfaces. The effect of chemical composition and structure were additionally discussed, as these are closely linked to the characteristic behavior of lignosulfonates.

In contrast to other technical lignin, lignosulfonates are water soluble due to an abundance of ionizable functional groups, which primarily comprise sulfonate groups, but also carboxylic acid groups. Hydrophobic groups are found in the skeletal lignin-structure, which most importantly include aromatic and residual aliphatic units, but also some oxygen containing groups. It is the balance of hydrophilic (ionizable) and hydrophobic groups that largely determines the behavior of lignosulfonates. HIC is a recently developed technique, which has been instrumental in determining the relative hydrophobicity of lignosulfonates.

Lignosulfonates are randomly branched polyelectrolytes that assume oblate spheroid shape in aqueous solution. Aggregation and self-association is reported to occur on the long edges, where the hydrophobic moieties are concentrated in the aggregate core and the anionic groups mostly extend into solution. Lignosulfonate-lignosulfonate interactions are determined by effects such as electrostatic 
repulsion, $\pi$ - $\pi$-interactions, and hydrogen bonding. Phenomena such as polyelectrolyte expansion and self-association are greatly affected by changes in $\mathrm{pH}$, ionic strength, temperature, and the presence of organic solvents. Changes that yield electrostatic shielding of anionic group (e.g., increasing ionic strength), reduce degree of dissociation (e.g., $\mathrm{pH}$ decrease) or increase the number of possible conformations (e.g., temperature increase) will usually result in enhanced aggregation.

Due to their amphiphilic property, lignosulfonates can adsorb on surfaces and interfaces. The adsorption equilibrium reportedly follows Langmuir isotherm, while a pseudo second-order kinetic was found to resemble the time-dependent adsorption most accurately. The mechanisms for dispersion stabilization were reported as introducing electrostatic repulsion, stearic hindrance, particle stabilization (Pickering emulsion), and the formation of viscoelastic interface layers. Key advancements have been made in understanding the dispersing and stabilization function of lignosulfonates, for example by studying surface and interfacial tension, zeta potential, and the mechanical response of interfacial films to deformation.

The main conclusion of this review is that the chemical structure of lignosulfonates is inherently linked to their behavior in aqueous solution and their performance as dispersion stabilizers. The balance between hydrophobic and hydrophilic moieties is a measure that can be used for fine-tuning lignosulfonates to specific applications. Increasing content of hydrophilic groups, for example by adding sulfonate or carboxylic acid groups, can not only augment water-solubility and specific charge density, but also enhance the ability to introduce charges at surfaces and to act as a complexing agent. A higher fraction of hydrophobic moieties on the other hand, as found in the residual skeletal lignin, may improve the ability of lignosulfonate to stabilize aqueous suspensions and emulsions, but it can also render the material more prone to salting out.

Controlling the composition of lignosulfonates is hence crucial for producing functional specialty chemicals. Various parameters may govern this chemistry, for example the choice of feedstock, pulping conditions, fractionation, and chemical modification. Some of the traditional challenges have been overcome by realizing cost-effective fractionation and purification. With the advancement of efficient upgrading and modification strategies, the range of application areas for lignosulfonates may be extended even further.

Funding: This research received no external funding.

Conflicts of Interest: The author declares no conflict of interest.

\section{References}

1. Aro, T.; Fatehi, P. Production and Application of Lignosulfonates and Sulfonated Lignin. ChemSusChem 2017, 10, 1861-1877. [CrossRef] [PubMed]

2. Macfarlane, A.; Mai, M.; Kadla, J.F. Bio-based chemicals from biorefining: Lignin conversion and utilisation. In Advances in Biorefineries; Waldron, K., Ed.; Woodhead Publishing: Sawston, UK, 2014; pp. 659-692.

3. Stern, T.; Schwarzbauer, P. Wood-based lignosulfonate versus synthetic polycarboxylate in concrete admixture systems: The perspective of a traditional pulping by-product competing with an oil-based substitute in a business-to-business market in central Europe. For. Prod. J. 2008, 58, 81-86.

4. Lauten, R.A.; Myrvold, B.O; Gundersen, S.A. New Developments in the Commercial Utilization of Lignosulfonates. Surfactants Renew. Resour. 2010, 269-283. [CrossRef]

5. Xu, C.; Ferdosian, F. Utilization of Lignosulfonate as Dispersants or Surfactants. In Conversion of Lignin into Bio-Based Chemicals and Materials; Xu, C., Ferdosian, F., Eds.; Springer Berlin Heidelberg: Berlin/Heidelberg, Germany, 2017; pp. 81-90.

6. Garguiak, J.D.; Lebo, S.E. Commercial Use of Lignin-Based Materials. In Lignin: Historical, Biological, and Materials Perspectives; American Chemical Society: Washington, DC, USA, 1999; Volume 742, pp. 304-320.

7. Miretzky, P.; Cirelli, A.F. Cr(VI) and Cr(III) removal from aqueous solution by raw and modified lignocellulosic materials: A review. J. Hazard. Mater. 2010, 180, 1-19. [CrossRef]

8. Alazigha, D.P.; Indraratna, B.; Vinod, J.S.; Heitor, A. Mechanisms of stabilization of expansive soil with lignosulfonate admixture. Transp. Geotech. 2018, 14, 81-92. [CrossRef] 
9. Ruwoldt, J.; Planque, J.; Øye, G. Lignosulfonate Salt Tolerance and the Effect on Emulsion Stability. ACS Omega 2020, 5, 15007-15015. [CrossRef]

10. Ouyang, X.; Qiu, X.; Lou, H.; Yang, D. Corrosion and Scale Inhibition Properties of Sodium Lignosulfonate and Its Potential Application in Recirculating Cooling Water System. Ind. Eng. Chem. Res. 2006, 45, 5716-5721. [CrossRef]

11. Blanck, G.; Cuisinier, O.; Masrouri, F. Soil treatment with organic non-traditional additives for the improvement of earthworks. Acta Geotech. 2014, 9, 1111-1122. [CrossRef]

12. Tsau, J.-S.; Syahputra, A.E.; Yaghoobi, H.; Grigg, R.B. Use of Sacrificial Agents in CO2 Foam Flooding Application. In SPE Annual Technical Conference and Exhibition; Society of Petroleum Engineers: Houston, TX, USA, 1999; p. 9.

13. Chiwetelu, C. Improving the Oil Recovery Efficacy of Lignosulfonate Solutions. J. Can. Pet. Technol. 1980, 19, 10. [CrossRef]

14. Vebi, M.; Hassan, A.; Hubert, H.; Markus, B.; Ireen, G.; Robert, B.; Karin, F.; Antje, P.; Thomas, R. Lignosulfonate-based polyurethane materials via cyclic carbonates: Preparation and characterization. Holzforschung 2020, 74, 203-211.

15. Hirose, S. Novel Epoxy Resins with Unsaturated Ester Chains Derived from Sodium Lignosulfonate. Macromol. Symp. 2015, 353, 31-38. [CrossRef]

16. Hu, J.-P.; Guo, M.-H. Influence of ammonium lignosulfonate on the mechanical and dimensional properties of wood fiber biocomposites reinforced with polylactic acid. Ind. Crop. Prod. 2015, 78, 48-57. [CrossRef]

17. Sixta, H. Handbook of Pulp; Wiley-vch: Weinheim, Germany, 2006.

18. Konduri, M.K.R.; Fatehi, P. Production of Water-Soluble Hardwood Kraft Lignin via Sulfomethylation Using Formaldehyde and Sodium Sulfite. ACS Sustain. Chem. Eng. 2015, 3, 1172-1182. [CrossRef]

19. Ouyang, X.; Ke, L.; Qiu, X.; Guo, Y.; Pang, Y. Sulfonation of Alkali Lignin and Its Potential Use in Dispersant for Cement. J. Dispers. Sci. Technol. 2009, 30,1-6. [CrossRef]

20. Huang, C.; Ma, J.; Zhang, W.; Huang, G.; Yong, Q. Preparation of Lignosulfonates from Biorefinery Lignins by Sulfomethylation and Their Application as a Water Reducer for Concrete. Polymers 2018, 10, 841. [CrossRef] [PubMed]

21. Myrvold, B.O. A new model for the structure of lignosulphonates: Part 1. Behaviour in dilute solutions. Ind. Crop. Prod. 2008, 27, 214-219. [CrossRef]

22. Li, T.; Takkellapati, S. The current and emerging sources of technical lignins and their applications. Biofuels, Bioprod. Biorefining 2018, 12, 756-787. [CrossRef]

23. Upton, B.M.; Kasko, A.M. Strategies for the Conversion of Lignin to High-Value Polymeric Materials: Review and Perspective. Chem. Rev. 2016, 116, 2275-2306. [CrossRef]

24. Chio, C.; Sain, M.; Qin, W. Lignin utilization: A review of lignin depolymerization from various aspects. Renew. Sustain. Energy Rev. 2019, 107, 232-249. [CrossRef]

25. Szalaty, T.J.; Klapiszewski, Ł.; Jesionowski, T. Recent developments in modification of lignin using ionic liquids for the fabrication of advanced materials-A review. J. Mol. Liq. 2020, 301, 112417. [CrossRef]

26. Laurichesse, S.; Avérous, L. Chemical modification of lignins: Towards biobased polymers. Prog. Polym. Sci. 2014, 39, 1266-1290. [CrossRef]

27. Jacquet, N.; Maniet, G.; Vanderghem, C.; Delvigne, F.; Richel, A. Application of Steam Explosion as Pretreatment on Lignocellulosic Material: A Review. Ind. Eng. Chem. Res. 2015, 54, 2593-2598. [CrossRef]

28. An, L.; Wang, G.; Jia, H.; Liu, C.; Sui, W.; Si, C. Fractionation of enzymatic hydrolysis lignin by sequential extraction for enhancing antioxidant performance. Int. J. Biol. Macromol. 2017, 99, 674-681. [CrossRef] [PubMed]

29. Daintith, J. Surfactant; Oxford University Press: Oxford, UK, 2008.

30. Paria, S.; Khilar, K.C. A review on experimental studies of surfactant adsorption at the hydrophilic solid-water interface. Adv. Colloid Interface Sci. 2004, 110, 75-95. [CrossRef] [PubMed]

31. Boerjan, W.; Ralph, J.; Baucher, M. Lignin Biosynthesis. Annu. Rev. Plant Biol. 2003, 54, 519-546. [CrossRef] [PubMed]

32. Qiu, X.; Yan, M.; Yang, D.; Pang, Y.; Deng, Y. Effect of straight-chain alcohols on the physicochemical properties of calcium lignosulfonate. J. Colloid Interface Sci. 2009, 338, 151-155. [CrossRef] [PubMed]

33. Ekeberg, D.; Gretland, K.S.; Gustafsson, J.; Bråten, S.M.; Fredheim, G.E. Characterisation of lignosulphonates and kraft lignin by hydrophobic interaction chromatography. Anal. Chim. Acta 2006, 565, 121-128. [CrossRef] 
34. Vishtal, A.G.; Kraslawski, A. Challenges in industrial applications of technical lignins. BioResources 2011, 6, 3547-3568.

35. Fredheim, G.E.; Christensen, B.E.; Braaten, S.M. Comparison of Molecular Weight and Molecular Weight Distributions of Softwood and Hardwood Lignosulfonates. J. Wood Chem. Technol. 2003, 23, 197-215.

36. Windeisen, E.; Wegener, G. 10.15-Lignin as Building Unit for Polymers. In Polymer Science: A Comprehensive Reference; Matyjaszewski, K., Möller, M., Eds.; Elsevier: Amsterdam, The Netherlands, 2012; pp. 255-265.

37. Myrvold, B.O. Free radical gelling reactions of lignosulfonates. Holzforschung 2015, 69, 1089-1096. [CrossRef]

38. Myrvold, B.O. Differences in solubility parameters and susceptibility to salting-out between softwood and hardwood lignosulfonates. Holzforschung 2016, 70, 1015-1021. [CrossRef]

39. Heitner, C.; Dimmel, D.; Schmidt, J. Lignin and Lignans: Advances in Chemistry; CRC Press: Cleveland, $\mathrm{OH}$, USA, 2016.

40. Rovio, S.; Kuitunen, S.; Ohra-Aho, T.; Alakurtti, S.; Kalliola, A.; Tamminen, T. Lignin oxidation mechanisms under oxygen delignification conditions. Part 2: Advanced methods for the detailed characterization of lignin oxidation mechanisms. Holzforschung 2011, 65, 575. [CrossRef]

41. Lachenal, D.; Fernandes, J.; Froment, P. Behaviour of residual lignin in kraft pulp during bleaching. J. Pulp Pap. Sci. 1995, 21, J173.

42. Kazzaz, A.E.; Feizi, Z.H.; Fatehi, P. Grafting strategies for hydroxy groups of lignin for producing materials. Green Chem. 2019, 21, 5714-5752. [CrossRef]

43. Myrvold, B.O. The Hansen solubility parameters of some lignosulfonates. World Acad. Sci. Eng. Technol. Trans. Energy Power Eng. 2014, 1, 261.

44. Valencia, P.J.S.; Marinez, L.E.B.; Merchancano, S.T.P. Molecular Modeling of Ammonium, Calcium, Sulfur, and Sodium Lignosulphonates in Acid and Basic Aqueous Environments. Braz. J. Phys. 2015, 45, 567-574. [CrossRef]

45. Laughlin, R.G. HLB, from a thermodynamic perspective. J. Soc. Cosmet. Chem. 1981, 32, 371-392.

46. Ensing, B.; Tiwari, A.; Tros, M.; Hunger, J.; Domingos, S.R.; Pérez, C.; Smits, G.; Bonn, M.; Bonn, D.; Woutersen, S. On the origin of the extremely different solubilities of polyethers in water. Nat. Commun. 2019, 10, 1-8. [CrossRef]

47. Holmberg, K. Natural surfactants. Curr. Opin. Colloid Interface Sci. 2001, 6, 148-159. [CrossRef]

48. Brauns, F.E.; Brauns, D.A. The Chemistry of Lignin: Supplement Volume Covering the Literature for the Years 1949-1958, 1st ed.; Academic Press: New York, NY, USA, 1960.

49. Kun, D.; Pukánszky, B. Polymer/lignin blends: Interactions, properties, applications. Eur. Polym. J. 2017, 93, 618-641. [CrossRef]

50. Fiorani, G.; Crestini, C.; Selva, M.; Perosa, A. Advancements and Complexities in the Conversion of Lignocellulose into Chemicals and Materials. Front. Chem. 2020, 8, 797. [CrossRef] [PubMed]

51. Fredheim, G.E.; Braaten, S.M.; Christensen, E.B. Molecular weight determination of lignosulfonates by size-exclusion chromatography and multi-angle laser light scattering. J. Chromatogr. A 2002, 942, 191-199. [CrossRef]

52. Kontturi, A.-K. Diffusion coefficients and effective charge numbers of lignosulphonate. Influence of temperature. J. Chem. Soc. Faraday Trans. 1 Phys. Chem. Condens. Phases 1988, 84, 4043-4047. [CrossRef]

53. Ruwoldt, J.; Simon, S.; Øye, G. Viscoelastic properties of interfacial lignosulfonate films and the effect of added electrolytes. Colloids Surfaces A: Physicochem. Eng. Asp. 2020, 606, 125478. [CrossRef]

54. Tolbert, A.; Akinosho, H.; Khunsupat, R.; Naskar, A.K.; Ragauskas, A.J. Characterization and analysis of the molecular weight of lignin for biorefining studies. Biofuels Bioprod. Biorewfining 2014, 8, 836-856. [CrossRef]

55. El Mansouri, N.-E.; Salvadó, J. Analytical methods for determining functional groups in various technical lignins. Ind. Crop. Prod. 2007, 26, 116-124. [CrossRef]

56. El Mansouri, N.-E.; Salvadó, J. Structural characterization of technical lignins for the production of adhesives: Application to lignosulfonate, kraft, soda-anthraquinone, organosolv and ethanol process lignins. Ind. Crop. Prod. 2006, 24, 8-16. [CrossRef]

57. Technical Association of the Pulp and Paper Industry (TAPPI) standard T 222 om-15. In Acid-Insoluble Lignin in Wood and Pulp; TAPPI Press: Atlanta, GA, USA, 2015.

58. Sluiter, A.; Hames, B.; Ruiz, R.; Scarlata, C.; Sluiter, J.; Templeton, D.; Crocker, D. Determination of structural carbohydrates and lignin in biomass. Lab. Anal. Proced. 2008, 1617, 1-16. 
59. Maekawa, E.; Ichizawa, T.; Koshijima, T. An Evaluation of the Acid-Soluble Lignin Determination in Analyses of Lignin by the Sulfuric Acid Method. J. Wood Chem. Technol. 1989, 9, 549-567. [CrossRef]

60. Gosselink, R.J.A.; Abächerli, A.; Semke, H.; Malherbe, R.; Käuper, P.; Nadif, A.; Van Dam, J. Analytical protocols for characterisation of sulphur-free lignin. Ind. Crop. Prod. 2004, 19, 271-281. [CrossRef]

61. Faix, O. Fourier Transform Infrared Spectroscopy. In Methods in Lignin Chemistry; Lin, S.Y., Dence, C.W., Eds.; Springer: Berlin/Heidelberg, Germany, 1992; pp. 83-109.

62. Boeriu, C.G.; Bravo, D.; Gosselink, R.J.; Van Dam, J.E. Characterisation of structure-dependent functional properties of lignin with infrared spectroscopy. Ind. Crop. Prod. 2004, 20, 205-218. [CrossRef]

63. Capanema, E.A.; Balakshin, A.M.Y.; Kadla, J.F. A Comprehensive Approach for Quantitative Lignin Characterization by NMR Spectroscopy. J. Agric. Food Chem. 2004, 52, 1850-1860. [CrossRef] [PubMed]

64. Pu, Y.; Cao, S.; Ragauskas, A.J. Application of quantitative 31P NMR in biomass lignin and biofuel precursors characterization. Energy Environ. Sci. 2011, 4, 3154-3166. [CrossRef]

65. Gupta, P.R.; McCarthy, J.L. Lignin. X.I.V. Gel Chromatography and the Distribution in Molecular Size of Lignin Sulfonates at Several Electrolyte Concentrations. Macromology 1968, 1, 236-244. [CrossRef]

66. Siochi, E.J.; Ward, T.C.; Haney, M.A.; Mahn, B. The absolute molecular weight distribution of hydroxypropylated lignins. Macromology 1990, 23, 1420-1429. [CrossRef]

67. Duval, A.; Molina-Boisseau, S.; Chirat, C. Fractionation of lignosulfonates: Comparison of ultrafiltration and ethanol solubility to obtain a set of fractions with distinct properties. Holzforschung 2015, 69, 127-134. [CrossRef]

68. Evtuguin, D.; Domingues, P.; Amado, F.L.; Neto, C.P.; Correia, A.F. Electrospray Ionization Mass Spectrometry as a Tool for Lignins Molecular Weight and Structural Characterisation. Holzforschung 1999, 53, 525-528. [CrossRef]

69. Qian, Y.; Deng, Y.; Guo, Y.; Yi, C.; Qiu, X. Determination of absolute molecular weight of sodium lignosulfonates (NaLS) by laser light scattering (LLS). Holzforschung 2013, 67, 265-271. [CrossRef]

70. Shen, Q.; Fu, Z.; Li, R.; Wu, Y. A study on the pyrolysis mechanism of a $\beta-\mathrm{O}-4$ lignin dimer model compound using DFT combined with Py-GC/MS. J. Therm. Anal. Calorim. 2020, 1-11. [CrossRef]

71. Brudin, S.; Schoenmakers, P. Analytical methodology for sulfonated lignins. J. Sep. Sci. 2010, 33, 439-452. [CrossRef]

72. Lebo, S.E.; Bråten, S.M.; Fredheim, G.E.; Lutnaes, B.F.; Lauten, R.A.; Myrvold, B.O.; McNally, T.J. Recent Advances in the Characterization of Lignosulfonates. In Characterization of Lignocellulosic Materials; Hu, T.Q., Ed.; Blackwell Publishing Ltd.: Hoboken, NJ, USA, 2008.

73. Sulaeva, I.; Vejdovszky, P.; Henniges, U.; Mahler, A.K.; Rosenau, T.; Potthast, A. Molar Mass Characterization of Crude Lignosulfonates by Asymmetric Flow Field-Flow Fractionation. ACS Sustain. Chem. Eng. 2018, 7, 216-223. [CrossRef]

74. Winowiski, T.; Lebo, S.; Gretland, K.; Gustafsson, J. Characterization of Sulfonated Lignin Dispersants by Hydrophobic Interactive Chromatography. J. ASTM Int. 2005, 2, 12915. [CrossRef]

75. Musl, O.; Sulaeva, I.; Bacher, M.; Mahler, A.K.; Rosenau, T.; Potthast, A. Hydrophobic Interaction Chromatography (HIC) in 2D-LC Characterization of Lignosulfonates. ChemSusChem 2020, 13, 4595-4604. [CrossRef] [PubMed]

76. Korntner, P.; Schedl, A.; Sumerskii, I.; Zweckmair, T.; Mahler, A.K.; Rosenau, T.; Potthast, A. Sulfonic Acid Group Determination in Lignosulfonates by Headspace Gas Chromatography. ACS Sustain. Chem. Eng. 2018, 6, 6240-6246. [CrossRef]

77. Grigg, R.; Bai, B. Calcium lignosulfonate adsorption and desorption on Berea sandstone. J. Colloid Interface Sci. 2004, 279, 36-45. [CrossRef] [PubMed]

78. Ratinac, K.R.; Standard, O.; Bryant, P. Lignosulfonate adsorption on and stabilization of lead zirconate titanate in aqueous suspension. J. Colloid Interface Sci. 2004, 273, 442-454. [CrossRef]

79. Nanthakumar, B.; Arinaitwe, E.; Pawlik, M. Adsorption of sodium lignosulfonates on hematite. Adsorption 2010, 16, 447-455. [CrossRef]

80. Ge, Y.; Li, Z.; Pang, Y.; Qiu, X. Influence of molecular mass of lignosulfonates on the resulting surface charges of solid particles. Int. J. Biol. Macromol. 2013, 52, 300-304. [CrossRef]

81. Liu, D.; Peng, Y. Understanding different roles of lignosulfonate in dispersing clay minerals in coal flotation using deionised water and saline water. Fuel 2015, 142, 235-242. [CrossRef] 
82. Tang, Q.; Zhou, M.; Yang, D.; Qiu, X. Effects of $\mathrm{pH}$ on aggregation behavior of sodium lignosulfonate (NaLS) in concentrated solutions. J. Polym. Res. 2015, 22, 50. [CrossRef]

83. Vainio, U.; Lauten, R.A.; Serimaa, R. Small-Angle X-ray Scattering and Rheological Characterization of Aqueous Lignosulfonate Solutions. Langmuir 2008, 24, 7735-7743. [CrossRef] [PubMed]

84. Qian, Y.; Deng, Y.; Yi, C.; Yu, H.; Qiu, X. Solution Behaviors and Adsorption Characteristics of Sodium Lignosulfonate Under Different Ph Conditions. BioResources 2011, 6, 4686-4695.

85. Vainio, U.; Lauten, R.A.; Haas, S.; Svedström, K.; Veiga, L.S.I.; Hoell, A.; Serimaa, R. Distribution of Counterions around Lignosulfonate Macromolecules in Different Polar Solvent Mixtures. Langmuir 2012, 28, 2465-2475. [CrossRef] [PubMed]

86. Yan, M.; Yang, D.; Deng, Y.; Chen, P.; Zhou, H.; Qiu, X. Influence of pH on the behavior of lignosulfonate macromolecules in aqueous solution. Colloids Surf. A Physicochem. Eng. Asp. 2010, 371, 50-58. [CrossRef]

87. Qin, Y.; Qiu, X.; Liang, W.; Yang, D. Investigation of Adsorption Characteristics of Sodium Lignosulfonate on the Surface of Disperse Dye Using a Quartz Crystal Microbalance with Dissipation. Ind. Eng. Chem. Res. 2015, 54, 12313-12319. [CrossRef]

88. Wang, Y. Adsorption and Inhibition Behavior of Calcium Lignosulfonate on Steel in $\mathrm{NaCl}+\mathrm{Ca}(\mathrm{OH})_{2}$ Solutions with Different $\mathrm{pH}$ Values. Int. J. Electrochem. Sci. 2016, 11, 6976-6992. [CrossRef]

89. Deng, Y.; Zhang, W.; Wu, Y.; Yu, H.; Qiu, X. Effect of Molecular Weight on the Adsorption Characteristics of Lignosulfonates. J. Phys. Chem. B 2011, 115, 14866-14873. [CrossRef]

90. Ge, Y.; Li, D.; Li, Z. Effects of Lignosulfonate Structure on the Surface Activity and Wettability to a Hydrophobic Powder. Bioresources 2014, 9, 9. [CrossRef]

91. Pita, F.; Castilho, A.M. Plastics floatability: Effect of saponin and sodium lignosulfonate as wetting agents. Polímeros 2019, 29, 29. [CrossRef]

92. Askvik, K.M. Complexation of Lignosulfonates with Multivalent Cations and Cationic Surfactants, and the Impact on Emulsion Stability. Ph.D. Thesis, University of Bergen, Bergen, Norway, 2000.

93. Megiatto, J.D.; Cerrutti, B.M.; Frollini, E. Sodium lignosulfonate as a renewable stabilizing agent for aqueous alumina suspensions. Int. J. Biol. Macromol. 2016, 82, 927-932. [CrossRef]

94. Askvik, K.M.; Gundersen, S.A.; Sjöblom, J.; Merta, J.; Stenius, P. Complexation between lignosulfonates and cationic surfactants and its influence on emulsion and foam stability. Colloids Surfaces A: Physicochem. Eng. Asp. 1999, 159, 89-101. [CrossRef]

95. Yang, D.; Qiu, X.; Pang, Y.; Zhou, M. Physicochemical Properties of Calcium Lignosulfonate with Different Molecular Weights as Dispersant in Aqueous Suspension. J. Dispers. Sci. Technol. 2008, 29, 1296-1303. [CrossRef]

96. Rana, D.; Neale, G.; Hornof, V. Surface tension of mixed surfactant systems: Lignosulfonate and sodium dodecyl sulfate. Colloid Polym. Sci. 2002, 280, 775-778. [CrossRef]

97. Park, S.; Lee, E.S.; Sulaiman, W.R.W. Adsorption behaviors of surfactants for chemical flooding in enhanced oil recovery. J. Ind. Eng. Chem. 2015, 21, 1239-1245. [CrossRef]

98. Ruwoldt, J.; Øye, G. Effect of Low-Molecular-Weight Alcohols on Emulsion Stabilization with Lignosulfonates. ACS Omega 2020, 5, 30168-30175. [CrossRef]

99. Gundersen, S. Langmuir surface and interface films of lignosulfonates and Kraft lignins in the presence of electrolyte and asphaltenes: Correlation to emulsion stability. Colloids Surf. A Physicochem. Eng. Asp. 2001, 182, 199-218. [CrossRef]

100. Okko, R.; Bodo, S.; Ralph, L. Isolation and fractionation of lignosulfonates by amine extraction and ultrafiltration: A comparative study. Holzforschung 2005, 59, 405-412.

101. Kienberger, M.; Demmelmayer, P.; Weißl, M.; Zankl, A.; Spirk, S. Biobased Support Layers for the Fractionation and Selective Extraction of Lignosulfonates. Solvent Extr. Ion Exch. 2019, 38, 132-141. [CrossRef]

102. Qian, C.; Fang, H.; Cui, P.; Cai, F.; Gao, X.; He, H.; Hu, X. Rapid determination of lignosulfonate depolymerization products by advanced polymer chromatography. J. Sep. Sci. 2019, 42, 2289-2297. [CrossRef]

103. Ouyang, X.P.; Zhang, P.; Tan, C.M.; Deng, Y.; Yang, D.J.; Qiu, X. Isolation of lignosulfonate with low polydispersity index. Chin. Chem. Lett. 2010, 21, 1479-1481. [CrossRef]

104. Ouyang, X.; Zhang, P.; Qiu, X.; Deng, Y.; Chen, P. Lignosulfonate Separation Using Preparative Column Chromatography. Ind. Eng. Chem. Res. 2011, 50, 10792-10799. [CrossRef] 
105. Humpert, D.; Ebrahimi, M.; Czermak, P. Membrane Technology for the Recovery of Lignin: A Review. Membranes 2016, 6, 42. [CrossRef] [PubMed]

106. Felicetta, V.F.; Ahola, A.; McCarthy, J.L. Lignin. VII. Distribution in Molecular Weight of Certain Lignin Sulfonates1a. J. Am. Chem. Soc. 1956, 78, 1899-1904. [CrossRef]

107. Leger, C.A.; Chan, F.D.; Schneider, M.H. Fractionation and characterisation of technical ammonium lignosulphonate. BioResources 2010, 5, 2239-2247.

108. Kontturi, A.-K.; Sundholm, G.; Nielsen, K.M.; Zingales, R.; Vikholm, I.; Urso, F.; Weidlein, J.; Zingaro, R.A. The Extraction and Fractionation of Lignosulfonates with Long Chain Aliphatic Amines. Acta Chem. Scand. 1986, 40, 121-125. [CrossRef]

109. Kontturi, A.-K.; Kontturi, K.; Niinikoski, P.; Sundholm, G.; Euranto, E.K.; Pettersson, T. Extraction of a Polyelectrolyte Using a Supported Liquid Membrane. I. Choice of a Suitable Carrier-Solvent System. Acta Chem. Scand. 1990, 44, 879-882. [CrossRef]

110. Kontturi, A.-K.; Kontturi, K.; Niinikoski, P.; Sundholm, G. Extraction of a Polyelectrolyte Using a Supported Liquid Membrane, II. Extraction and Fractionation of Lignosulfonate. Acta Chem. Scand. 1990, 44, 883-891. [CrossRef]

111. Rojas, O.; Salager, J.-L. Surface activity of bagasse lignin derivatives found in the spent liquor of soda pulping plants. Tappi J. 1994, 77, 169-174.

112. Myrvold, B.O. Salting-out and salting-in experiments with lignosulfonates (LSs). Holzforschung 2013, 67, 549-557. [CrossRef]

113. Glas, D.; Van Doorslaer, C.; Depuydt, D.; Liebner, F.; Rosenau, T.; Binnemans, K.; De Vos, D.E. Lignin solubility in non-imidazolium ionic liquids. J. Chem. Technol. Biotechnol. 2014, 90, 1821-1826. [CrossRef]

114. Rezanowich, A.; Goring, D. Polyelectrolyte expansion of a lignin sulfonate microgel. J. Colloid Sci. 1960, 15, 452-471. [CrossRef]

115. Qian, Y.; Deng, Y.; Guo, Y.; Li, H.; Qiu, X. Light scattering characterization of lignosulfonate structure in saline solutions. Holzforschung 2015, 69, 377-383. [CrossRef]

116. Myrvold, B.O. The polyelectrolyte behavior of randomly branched lignosulfonates. Tappi J. 2007, 6, 10-14.

117. Deng, Y.; Wu, Y.; Qian, Y.; Ouyang, X.; Yang, D.; Qiu, X. Adsorption and desorption behaviors of lignosulfonate during the self-assembly of multilayers. BioResources 2010, 5, 1178-1196.

118. Li, H.; Deng, Y.; Ye, H.; Xiao, L.; Qiu, X. Effect of Temperature on Polyelectrolyte Expansion of Lignosulfonate. Bioresources 2014, 10, 575-587. [CrossRef]

119. Rezanowich, A.; Yean, W.Q.; Goring, D.A.I. High resolution electron microscopy of sodium lignin sulfonate. J. Appl. Polym. Sci. 1964, 8, 1801-1812. [CrossRef]

120. Deng, Y.; Feng, X.; Yang, D.; Yi, C.; Qiu, X. Pi-Pi stacking of the aromatic groups in lignosulfonates. BioResources 2012, 7, 1145-1156.

121. Qiu, X.; Kong, Q.; Zhou, M.; Yang, D. Aggregation Behavior of Sodium Lignosulfonate in Water Solution. J. Phys. Chem. B 2010, 114, 15857-15861. [CrossRef]

122. Myrvold, B.O. Evidence for a very slow disaggregation of lignosulfonates. Holzforschung 2015, 69, 9-16. [CrossRef]

123. Qian, Y.; Deng, Y.; Qiu, X.; Huang, J.; Yang, D. Aggregation of sodium lignosulfonate above a critical temperature. Holzforschung 2014, 68, 641-647. [CrossRef]

124. Li, B.; Ouyang, X.P. Structure and properties of Lignosulfonate with different molecular weight isolated by gel column chromatography. Adv. Mater. Res. Trans Tech. Publ. 2012, 554, 2024-2030. [CrossRef]

125. Zhukova, O.V.; Medvedeva, V.V.; Semchikov, Y.D. Gelation in sodium lignosulfonate solutions in the presence of a hexavalent chromium salt. Russ. J. Appl. Chem. 2008, 81, 2162-2165. [CrossRef]

126. Felber, B.J. Factors Affecting the Kinetics of Gelation of Lignosulfonate and the Measurement of the Heats of Association of Transition Metal Complexes of Ethylene-Maleic Acid. PhD Thesis, Oklahoma State University, Stillwater, OK, USA, 1980.

127. Narron, R.; Wolken, G.; Gargulak, J. Accelerated Polymerization of Ammonium Lignosulfonate from Loblolly Pine. For. Prod. J. 2020, 70, 134-142.

128. Zulfikar, M.A.; Wahyuningrum, D.; Lestari, S. Adsorption of Lignosulfonate Compound from Aqueous Solution onto Chitosan-Silica Beads. Sep. Sci. Technol. 2013, 48, 1391-1401. [CrossRef] 
129. Bai, B.; Grigg, R.B. Kinetics and Equilibria of Calcium Lignosulfonate Adsorption and Desorption onto Limestone. In SPE International Symposium on Oilfield Chemistry; Society of Petroleum Engineers: The Woodlands, TX, USA, 2005; p. 11.

130. Pang, Y.-X.; Qiu, X.; Yang, D.; Lou, H. Influence of oxidation, hydroxymethylation and sulfomethylation on the physicochemical properties of calcium lignosulfonate. Colloids Surf. A Physicochem. Eng. Asp. 2008, 312, 154-159. [CrossRef]

131. Yan, M.; Yang, N. Adsorption Mechanism of Lignosulfonate at the Air/Liquid Interface. J. Braz. Chem. Soc. 2015, 26, 555-561. [CrossRef]

132. Simon, S.; Saadat, M.; Ruwoldt, J.; Dudek, M.; Ellis, R.J.; Øye, G. Lignosulfonates in Crude Oil Processing: Interactions with Asphaltenes at the Oil/Water Interface and Screening of Potential Applications. ACS Omega 2020, 5, 30189-30200. [CrossRef]

133. Zaki, N.N.; Ahmed, N.S.; Nassar, A.M. Sodium Lignin Sulfonate to Stabilize Heavy Crude Oil-In-Water Emulsions for Pipeline Transportation. Pet. Sci. Technol. 2000, 18, 1175-1193. [CrossRef]

134. Verruto, V.J.; Le, R.K.; Kilpatrick, P.K. Adsorption and Molecular Rearrangement of Amphoteric Species at Oil-Water Interfaces. J. Phys. Chem. B 2009, 113, 13788-13799. [CrossRef]

135. Freer, E.M.; Radke, C.J. Relaxation of Asphaltenes at the Toluene/Water Interface: Diffusion Exchange and Surface Rearrangement. J. Adhes. 2004, 80, 481-496. [CrossRef]

136. Keleşoğlu, S.; Ponce, A.B.; Sørland, G.H.; Simon, S.; Paso, K.; Sjöblom, J. Rheological properties of highly concentrated dense packed layer emulsions (w/o) stabilized by asphaltene. J. Pet. Sci. Eng. 2015, 126, 1-10. [CrossRef]

137. Ouyang, X.; Deng, Y.; Qian, Y.; Zhang, P.; Qiu, X. Adsorption Characteristics of Lignosulfonates in Salt-Free and Salt-Added Aqueous Solutions. Biomacromolecules 2011, 12, 3313-3320. [CrossRef] [PubMed]

138. Bai, B.; Wu, Y.; Grigg, R.B. Adsorption and Desorption Kinetics and Equilibrium of Calcium Lignosulfonate on Dolomite Porous Media. J. Phys. Chem. C 2009, 113, 13772-13779. [CrossRef]

139. Zulfikar, M.A.; Setiyanto, H.; Djajanti, S.D. Effect of temperature and kinetic modelling of lignosulfonate adsorption onto powdered eggshell in batch systems. Songklanakarin J. Sci. Technol. 2013, 35, 1-31.

140. Klapiszewski, Ł.; Zdarta, J.; Szatkowski, T.; Wysokowski, M.; Nowacka, M.; Szwarc-Rzepka, K.; Bartczak, P.; Siwińska-Stefańska, K.; Ehrlich, H.; Jesionowski, T. Silica/lignosulfonate hybrid materials: Preparation and characterization. Open Chem. 2014, 12, 719-735. [CrossRef]

141. Li, H.; Huang, G.; An, C.; Zhang, W.-X. Kinetic and equilibrium studies on the adsorption of calcium lignosulfonate from aqueous solution by coal fly ash. Chem. Eng. J. 2012, 200, 275-282. [CrossRef]

142. Li, J.; Li, H.; Yuan, Z.; Fang, J.; Chang, L.; Zhang, H.; Li, C. Role of sulfonation in lignin-based material for adsorption removal of cationic dyes. Int. J. Biol. Macromol. 2019, 135, 1171-1181. [CrossRef]

143. Banfill, P.F.G.; Bowen, P.; Flatt, R.; Galmiche, L.; Houst, Y.; Kauppi, A.; Lafuma, F.; Livesey, P.; Mäder, U.; Myrvold, B. Improved superplasticisers for high performance concrete: The Superplast project. In Proceedings of the 12th International Congress on the Chemistry of Cement, Conseil National de Recherches du Canada, Montreal, QC, Canada, 8-13 July 2007; p. fin00344.

144. Gundersen, S.A. Lignosulfonates and Kraft Lignins as Oil-in-Water Emulsion Stabilizers; Department of Chemistry, University of Bergen: Bergen, Norway, 2000.

145. Ström, G.; Stenius, P. Formation of complexes, colloids and precipitates in aqueous mixtures of lignin sulphonate and some cationic polymers. Colloids Surf. 1981, 2, 357-371. [CrossRef]

146. Fredheim, G.E.; Christensen, B.E. Polyelectrolyte Complexes: Interactions between Lignosulfonate and Chitosan. Biomacromolecules 2003, 4, 232-239. [CrossRef]

147. Luo, H.; Shen, Q.; Ye, F.; Cheng, Y.-F.; Mezgebe, M.; Qin, R.-J. Structure and properties of layer-by-layer self-assembled chitosan/lignosulfonate multilayer film. Mater. Sci. Eng. C 2012, 32, 2001-2006. [CrossRef]

148. Askvik, K.M.; Hetlesæther, S.; Sjöblom, J.; Stenius, P. Properties of the lignosulfonate-surfactant complex phase. Colloids Surf. A Physicochem. Eng. Asp. 2001, 182, 175-189. [CrossRef]

149. Manasrah, K.; Neale, G.; Hornof, V. Properties of mixed surfactant solutions containing petroleum sulfonates and lignosulfonates. Cellul. Chem. Technol. 1985, 19, 291-299.

150. Hornof, V.; Neale, G.; Margeson, J.; Chiwetelu, C. Lignosulfonate-based mixed surfactants for low interfacial tension. Cellul. Chem. Technol. 1984, 18, 297-303.

151. Hong, S.; Bae, J.; Lewis, G. An Evaluation of Lignosulfonate as a Sacrificial Adsorbate in Surfactant Flooding. SPE Reserv. Eng. 1987, 2, 17-27. [CrossRef] 
152. Hong, S.; Bae, J. Field Experiment of Lignosulfonate Preflushing for Surfactant Adsorption Reduction. SPE Reserv. Eng. 1990, 5, 467-474. [CrossRef]

153. Nyman, V.; Rose, G.; Ralston, J. The colloidal behaviour of kraft lignin and lignosulfonates. Colloids Surfaces 1986, 21, 125-147. [CrossRef]

154. De Oliveira, F.; Ramires, E.C.; Frollini, E.; Belgacem, M.N. Lignopolyurethanic materials based on oxypropylated sodium lignosulfonate and castor oil blends. Ind. Crop. Prod. 2015, 72, 77-86. [CrossRef]

155. Qiu, X.; Zeng, W.; Liang, W.; Xue, Y.; Hong, N.; Li, Y. Sulfobutylated Lignosulfonate with Ultrahigh Sulfonation Degree and Its Dispersion Property in Low-Rank Coal-Water Slurry. J. Dispers. Sci. Technol. 2015, 37, 472-478. [CrossRef]

156. Matsushita, Y. Conversion of technical lignins to functional materials with retained polymeric properties. J. Wood Sci. 2015, 61, 230-250. [CrossRef]

157. Wang, Y.-Y.; Meng, X.; Pu, Y.; Ragauskas, A.J. Recent Advances in the Application of Functionalized Lignin in Value-Added Polymeric Materials. Polymers 2020, 12, 2277. [CrossRef]

158. Thielemans, W.; Wool, R.P. Lignin Esters for Use in Unsaturated Thermosets: Lignin Modification and Solubility Modeling. Biomacromolecules 2005, 6, 1895-1905. [CrossRef] [PubMed]

159. Gao, W.; Inwood, J.P.W.; Fatehi, P. Sulfonation of Phenolated Kraft Lignin to Produce Water Soluble Products. J. Wood Chem. Technol. 2019, 39, 225-241. [CrossRef]

160. Konduri, M.K.; Fatehi, P. Alteration in interfacial properties and stability of coal water slurry by lignosulfonate. Powder Technol. 2019, 356, 920-929. [CrossRef]

161. Tang, Y.; Lin, T.; Ai, S.; Li, Y.; Zhou, R.; Peng, Y. Super and selective adsorption of cationic dyes using carboxylate-modified lignosulfonate by environmentally friendly solvent-free esterification. Int. J. Biol. Macromol. 2020, 159, 98-107. [CrossRef] [PubMed]

162. Mahmood, N.; Yuan, Z.; Schmidt, J.; Souzanchi, S. Depolymerization of lignins and their applications for the preparation of polyols and rigid polyurethane foams: A review. Renew. Sustain. Energy Rev. 2016, 60, 317-329. [CrossRef]

163. Yanhua, J.; Weihong, Q.; Zongshi, L.; Lubai, C. A Study on the Modified Lignosulfonate from Lignin. Energy Sources 2004, 26, 409-414. [CrossRef]

164. Zhou, H.; Yang, D.; Wu, X.; Deng, Y.; Qiu, X. Physicochemical properties of sodium lignosulfonates (NaLS) modified by laccase. Holzforschung 2012, 66, 825-832. [CrossRef]

165. Zhou, H.; Yang, D.; Qiu, X.; Wu, X.; Li, Y. A novel and efficient polymerization of lignosulfonates by horseradish peroxidase/H2O2 incubation. Appl. Microbiol. Biotechnol. 2013, 97, 10309-10320. [CrossRef]

166. Kalliola, A.; Asikainen, M.; Talja, R.; Tamminen, T. Experiences of Kraft Lignin Functionalization by Enzymatic and Chemical Oxidation. Bioresources 2014, 9, 7336-7351. [CrossRef]

Publisher's Note: MDPI stays neutral with regard to jurisdictional claims in published maps and institutional affiliations.

(C) 2020 by the author. Licensee MDPI, Basel, Switzerland. This article is an open access article distributed under the terms and conditions of the Creative Commons Attribution (CC BY) license (http://creativecommons.org/licenses/by/4.0/). 